Discussion Papers in Economics

Factor Income Taxation, Growth, and Investment Specific Technological Change

\author{
Monisankar Bishnu
}

Chetan Ghate

Pawan Gopalakrishnan

January 2013

Discussion Paper 13-04

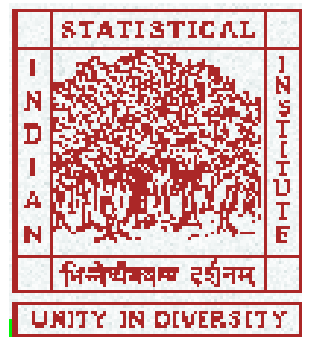

Indian Statistical Institute, Delhi

Economics and Planning Unit

7, S. J. S. Sansanwal Marg, New Delhi 110016, India 


\title{
Factor Income Taxation, Growth, and Investment Specific Technological Change*
}

\author{
Monisankar Bishnu ${ }^{\dagger} \quad$ Chetan Ghate \\ Pawan Gopalakrishnan ${ }^{\S}$
}

January 18, 2013

\begin{abstract}
We construct a tractable endogenous growth model with production externalities in which the public capital stock augments investment specific technological change. We characterize the first best fiscal policy and show that there exist several labor and capital tax-subsidy combinations that decentralize the planner's growth rate. The optimal factor income tax mix is therefore indeterminate which gives the planner the flexibility to choose policy rules from a large set. Our model explains why many advanced economies experiencing similar growth rates have widely varying factor income tax rates.
\end{abstract}

Keywords : Investment Specific Technological Change, Endogenous Growth, Factor Income Taxation, Welfare, First best fiscal policy, Indeterminacy.

JEL Codes: E2; E6; H2; O4

${ }^{*}$ We thank Partha Sen, Aditya Goenka, Javed I. Ahmed, Joydeep Bhattacharya, Chetan Dave, Alok Johri, Premachandra Athukorala, Rajesh Singh, Prabal Roy Chowdhury, Noritaka Maebayashi and seminar participants at the 7th Annual Growth and Development Conference (ISI -Delhi), ISI Kolkata, the Australian National University, the 11th Louis-André Gérard-Varet Conference (Marseilles), and the 2012 Asian Meeting of the Econometric Society (New Delhi) for insightful comments. An earlier version of this paper was titled "Distortionary Taxes and Public Investment in a Model of Endogenous Investment Specific Technological Change".

${ }^{\dagger}$ Economics and Planning Unit, Indian Statistical Institute, New Delhi - 110016, India. Fax: 91-11-41493981. E-mail: mbishnu@isid.ac.in. Tel: 91-11-41493935.

${ }^{\ddagger}$ Corresponding Author: Economics and Planning Unit, Indian Statistical Institute, New Delhi - 110016, India; ICRIER, Core 6A, 4th Floor, India Habitat Center, Lodhi Road, New Delhi. Tel: 91-11-4149-3938. Fax: 91-11-4149-3981. E-mail: cghate@isid.ac.in.

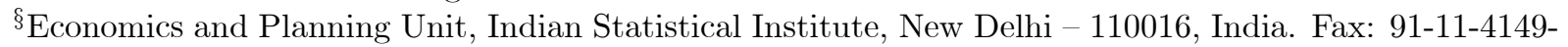
3981. E-mail: pawan9r@isid.ac.in. Tel: 91-11-27568306. 


\section{Introduction}

Why do advanced economies with roughly identical growth rates have widely varying factor income tax rates? In this paper, we develop a tractable endogenous growth model to understand this question. Figure (1) plots the average annual real GDP growth rate from 1990 to 2007 against the factor income tax ratio for several advanced economies. ${ }^{1}$ Average growth for all countries (excluding Ireland) falls between $0.875 \%$ and $2.462 \%$. The standard deviation of the average real GDP growth rates is 0.878 (excluding Ireland, the standard deviation is 0.4756) which indicates low dispersion of growth rates. What is striking however is that the range in the ratios of the average capital income tax rate to the average labor income tax rate in these economies is much more pronounced: 0.3951 to $1.725 .^{2}$ In other words, there is more dispersion in factor income tax ratios relative to dispersion in growth.

This is reinforced by Figure (2) which plots the difference between the average factor income tax rates for these economies. Despite having similar growth rates, what is striking is that whereas the difference between factor income taxes is large in some countries, it is quite small in others. ${ }^{3}$

\section{[Insert Figure 1 and 2]}

Finally, Figure (3) plots the levels of factor income tax rates across the G7 countries. The incidence of factor income taxation is quite disparate. In the US, UK, Canada, and Japan, the tax on capital income is greater than the tax on labor income. In contrast, for Germany, Italy, and France, the reverse is true.

\section{[Insert Figure 3]}

To explain these observations, we construct an endogenous growth model in which public investment, financed by distortionary taxes, augments investment specific technological

\footnotetext{
${ }^{1}$ The growth rates are calculated from the OECD (2012) database: see Table (VXVOB). The countries are: Austria (AUS), Belgium (BEL), Canada (CAN), Denmark (DEN), Finland (FIN), France (FRA), Germany (GER), Greece (GRE), Ireland (IRE), Italy (ITA), Japan (JPN), Netherlands (NET), Portugal (PRT), Spain (SP), Sweden (SWE), United Kingdom (UK) and United States of America (USA). The base year is 2000

${ }^{2}$ Canada and Japan have data on capital and labor income tax estimates based on the approach used in Mendoza et al. (1994) and Trabandt and Uhlig (2009) from 1965 to 1996. For Germany, United Kingdom and United States of America, data is from 1965 to 2007. For France, the data is from 1970 to 2007. For Italy, the data is from 1980 to 2007. For Austria, Belgium, Denmark, Finland, Netherlands, Portugal and Sweden, the data is from from 1995 to 2007. For Spain and Greece, the data is from 2000 to 2007. Finally, for Ireland, the data is from 2002 to 2007.

${ }^{3}$ The data on factor income taxes are from Mendoza et al. (1994) and Trabandt and Uhlig (2009). The latter have used the approach in Mendoza et al. (1994) to estimate the tax rates for 17 OECD nations till 2007.
} 
change (ISTC). We build on a series of seminal papers by Huffman (2007, 2008) who explicitly models the mechanism by which the real price of capital falls when investment specific technological occurs. A growing literature has attributed the importance of investment specific technological change to long run growth (see Greenwood et al. (1997, 2000); Whelan (2003)). Investment specific technological change refers to technological change which reduces the real price of capital goods. Greenwood et al. (1997, 2000) show that once the falling price of real capital goods is taken into account, this explains most of the observed growth in output in the US, with relatively little being left over to be explained by total factor productivity. ${ }^{4}$

Huffman (2008) builds a neoclassical growth model with investment specific technological change. Labor is used in research activities in order to increase investment specific technological change. In particular, the changing relative price of capital is driven by research activity, undertaken by labor effort. Higher research spending in one period lowers the cost of producing the capital good in the next period. ${ }^{5}$ Investment specific technological change is thus endogenous in the model, since employment can either be undertaken in a research sector or a production sector. His model includes capital taxes, labor taxes, and investment subsidies that are used to finance a lump-sum transfer. Huffman (2008) finds that a positive capital tax that is larger than a positive investment subsidy along with zero labor tax can replicate the first best allocation.

In our model, we embed production externalities into a model of growth and endogenous investment specific technological change. In particular, we assume that the public capital stock has a direct effect on investment specific technological change (ISTC) as a positive externality. ${ }^{6}$ We assume that public investment is financed by distortionary taxes thereby allowing a role for factor income taxes to generate growth endogenously in the presence of investment specific technological change. The link between factor income taxation and investment specific technological change is therefore explicit in our model.

In addition, we assume that the presence of labor and aggregate private capital externalities also affect investment specific technological change. This assumption is motivated by Greenwood et al. (1997), who show that the real price of capital equipment in the US - since

\footnotetext{
${ }^{4}$ Other authors, such as Gort et al. (1999) distinguish between equipment specific technological change and structure specific technological change. These authors show that $15 \%$ of US economic growth rate can be attributed to structure specific technological change in the post war period, while equipment-specific technological progress accounts for $37 \%$ of US growth. This implies $52 \%$ of US economic growth can be attributed to technological progress in new capital goods.

${ }^{5}$ Krusell (1998) also builds a model in which the decline in the relative price of equipment capital is a result of $R \& D$ decisions at the level of private firms.

${ }^{6}$ Our setup also allows investment specific technological change to enhance the accumulation of public capital. For instance, providing better infrastructure today reduces the cost of providing public capital in the future.
} 
1950 - has fallen alongside a rise in the investment-GNP ratio, we assume that the aggregate stock of capital also exhibits a positive externality in investment specific technological change through the aggregate capital output ratio. Greenwood et al. (1997, p. 342) say: "The negative co-movement between price and quantity.....can be interpreted as evidence that there has been significant technological change in the production of new equipment. Technological advances have made equipment less expensive, triggering increases in the accumulation of equipment both in the short and long run." Finally, we assume that the specialized labor input in the research sector exerts an externality in the production of the first sector, the final good. Our main result is that the differences in factor income taxes that we observe empirically can be explained well when we account for the above externalities in a model of endogenous investment specific technological change.

In our model, a final good sector produces a final good, using private capital, and labor. Labor supply is composite in the sense that one type of labor activity is devoted to final good production, and the other to research which directly reduces the real price of capital goods in the next period. ${ }^{7}$ The agent optimally chooses each labor activity. The second sector captures the effect of public capital and the private capital stocks and research activity on reducing the real price of capital goods. In the planner's problem, we assume that public investment is financed by a proportional income tax. We characterize the balanced growth path (BGP) and show that the growth maximizing tax rate is determined by the relative importance of the public capital output ratio vis-a-vis the private capital output ratio in the investment specific technological change function. This characterizes the first best fiscal policy in the model. The implication of this is that if a planner was to choose the tax rate, he could maximize long run growth as long as the tax rate equals the relative contribution of public capital to investment specific technological change.

We then decentralize the planner's allocations. We assume that public investment is financed by distortionary factor income taxes on capital and labor income. We show that there is an indeterminate combination of capital tax rates and the labor tax rates that can replicate the first-best allocation. This result is not surprising since we confine ourselves to the first best fiscal policy that implements the planner's allocations. What is novel is that we show how the magnitudes of the externalities have a bearing on the optimal tax mix. Our main results can be summarized as follows:

- When there are no production externalities, equal factor incomes always yield the first

\footnotetext{
${ }^{7}$ A real life example that motivates this assumption is the skill required for advanced manufacturing jobs. Skilled factory workers today are typically "hybrid-workers": they are both machinists as well as computer programmers. For instance, in the US metal-fabricating sector, workers not only use cutting tools to shape a raw piece of metal, but they also write the computer code that instructs the machine to increase the speed of such operations. See Davidson (2012).
} 
best fiscal policy.

- When there are no production externalities, under a simple parametric restriction, both equal factor income taxes and unequal factor income taxes yield the first best fiscal policy.

- In the presence of production externalities, different combinations of unequal factor income taxes restore the first best. In the limit, as the effect of externalities diminishes, then the optimal tax rates converge.

Intuitively, the higher is the externality associated with the specialized labor input in the research sector (which exerts an externality in the production of the first sector, the final good), the lower is the optimal tax on capital for a given tax on labor income. This is because agents - by taking this externality as given - under-fund capital accumulation. A lower tax on capital income incentivizes capital accumulation and restores the planner's growth rate. The difference between both factor income taxes declines as the effect of the externality is reduced. Similarly, when the externality effects from the aggregate stocks (public and private) increase, these stocks increase the level of investment specific technological change. However, because agents do not internalize these spillovers from the aggregate stocks, they under-fund capital accumulation relative to the efficient growth rate. To incentivize capital accumulation, the planner sets a low optimal tax on capital income. In the limiting case (when there are no externalities) we show that equal factor income taxes always restore the planner's growth rates.

Our framework allows also us to Pareto rank the first best fiscal policy. We show numerically that the departure of the welfare maximizing tax rate from the first best tax policy can be decomposed into 1) the effect because of externalities, and 2) the effect because due to $n_{2}$. We show that both production externalities and endogenous ISTC imply departures from the first best policy.

Our paper is related to two strands of the literature on fiscal policy and long run growth in the neoclassical framework. The first literature - started by Barro (1990) and Futagami, Morita, and Shibata (1993) - incorporate a public input - such as public infrastructure - that directly augments production. In Barro (1990), public services are a flow; while in Futagami, Morita, and Shibata (1993), public capital accumulates. However, in the large literature on public capital and its impact on growth spawned by these papers, the public input, whether it is modeled as a flow or a stock, doesn't directly influence the real price of capital goods. ${ }^{8}$ Because public capital affects the real price of capital explicitly,

\footnotetext{
${ }^{8}$ For instance, in Ott and Turnovsky (2006) - who use the flow of public services to model the public
} 
this means that the public input affects future output through its effect on both future investment specific technological change, as well as future private capital accumulation. Our main methodological contribution is that we merge the public capital/endogenous growth literature with the endogenous investment specific technological change literature. To the best of knowledge, whereas distortionary taxes have been exogenously imposed to correct for externalities in the literature, our model is the first attempt to explain how differences in factor income taxes across countries can be explained by the existence of production externalities.

The rest of the paper proceeds as follows. Section 2 develops the basic model structure followed by characterizing the planner's model, the competitive equilibrium and some numerical experiment under unequal factor income taxes that shows how the magnitude of externalities in the model is crucial to the optimal tax mix. Section 3 concludes.

\section{The Model}

Consider an economy that is populated by identical representative agents, who at each period $t$, derive utility from consumption of the final good $C_{t}$ and leisure $\left(1-n_{t}\right)$. The term $n_{t}$ represents the fraction of time spent at time $t$ in employment. The discounted life-time utility, $U$, of an infinitely lived representative agent is given by

$$
U=\sum_{t=0}^{\infty} \beta^{t}\left[\log C_{t}+\log \left(1-n_{t}\right)\right]
$$

where $\beta \in(0,1)$ denotes the period-wise discount factor. There is no population growth in the economy and the total supply of labor for the representative agent at any time $t$ is given by $n_{t}$ such that

$$
n_{t} \equiv n_{1 t}+n_{2 t},
$$

where $n_{1 t}$ is labor allocated for final goods production and $n_{2 t}$ is labor allocated for enhancing investment specific technological change. The representative agent however is not aware that his allocation of labor towards $n_{2 t}$ also influences productivity of final goods production.

The final good is therefore produced by a standard production function with capital $K_{t}$, $n_{1 t}$, and aggregate $n_{2 t}$ entering as an externality, which we denote by $\bar{n}_{2 t}$. The key difference is that the planner internalizes the externality from $n_{2}$ in direct production, while agents do

input - and Chen (2006), Fischer and Turnovsky (1998) - who use stock of public capital - the shadow price of private capital is a function of public and private capital. 
not. The production function is given by

$$
Y_{t}=\underline{A} K_{t}^{\alpha} n_{1 t}^{1-\alpha} \underbrace{\left(n_{2 t}^{1-\alpha}\right)^{\xi}}_{\text {Externality }}
$$

where $\underline{A}>0$ is a scalar that denotes the exogenous level of productivity, $\alpha \in(0,1)$ is the share of output paid to capital, and $\xi>0$ is the externality parameter capturing the effect that $n_{2}$ has on direct production. When $\xi>0$, the planner internalizes the effect that $n_{2}$ has on direct production. When $\xi=0$, there is no externality from $n_{2}$ on the production of the final good. Note, in this framework, as in Huffman (2008) the two labor activities $n_{1 t}$ and $n_{2 t}$ are assumed to be equally skilled, but are optimally allocated across different activities by households. ${ }^{9}$

Private capital accumulation grows according to the standard law of motion augmented by investment specific technological change,

$$
K_{t+1}=(1-\delta) K_{t}+I_{t} Z_{t}
$$

where $\delta \in[0,1]$ denotes the rate of depreciation of capital and $I_{t}$ represents the amount of total output allocated towards private investment at time period $t$. $Z_{t}$ represents investmentspecific technological change. The higher the value of $Z_{t}$, the lower is the cost of accumulating capital in the future. Hence $Z_{t}$ also can be viewed as the inverse of the price of per-unit private capital at time period $t$. Thus at every period $t, Z_{t}$ augments investment $I_{t}$. $I_{t} Z_{t}$ thus represents the effective amount of investment driving capital accumulation in time period $t+1$.

In addition to labor time deployed by the representative firm towards $R \& D$, the public capital stock, $G$, plays a crucial role in lowering the price of capital accumulation. Typically, the public input is seen as directly affecting final production - either as a stock or a flow (e.g., see Futagami, Morita, and Shibata (1993), Chen (2006), Fischer and Turnovsky (1997, 1998), and Eicher and Turnovsky (2000)). Instead, we assume that the public input facilitates investment specific technological change. This means that the public input affects future output through future private capital accumulation directly. In the above literature, the public input affects current output directly.

We assume that in every period, public investment is funded by total tax revenue. Public

\footnotetext{
${ }^{9}$ Other papers in the literature - such as Reis (2011) - also assume two types of labor affecting production. In Reis (2011), one form of labor is the standard labor input, while the other labor input is entrepreneurial labor.
} 
capital therefore evolves according to

$$
G_{t+1}=(1-\delta) G_{t}+I_{t}^{g} Z_{t}
$$

where $G_{t+1}$ denotes the public capital stock in $t+1$, and $I_{t}^{g}$ denotes the level of public investment made by the government in time period $t$ :

$$
I_{t}^{g}=\tau Y_{t}
$$

where $\tau \in(0,1)$ is the proportional tax rate. We assume that $Z_{t}$ augments $I_{t}^{g}$ in the same way as $I_{t}$ since it enables us to analyze the joint endogeneity of $Z$ and $G$. To derive the balanced growth path, we further assume that the period wise depreciation rate $\delta \in[0,1]$ is same for both private capital and public capital.

\subsection{Investment Specific Technological Change}

To capture the effect of public capital on research and development, we assume that $Z$ grows according to the following law of motion,

$$
Z_{t+1}=B n_{2 t}{ }^{\theta} Z_{t}^{\gamma} \underbrace{\left\{\left(\frac{G_{t}}{Y_{t-1}}\right)^{\mu}\left(\frac{K_{t}}{Y_{t-1}}\right)^{1-\mu}\right\}^{1-\gamma}}_{\text {Externality }} .
$$

Here, $B$ stands for an exogenously fixed scale productivity parameter and $\mu \in(0,1)$ captures the impact of public investments on investment specific technological change. We assume that the parameters, $\theta \in(0,1)$ and $\gamma \in(0,1) ; \theta$ stands for the weight attached to research effort and $\gamma$ is the level of persistence the current year's level of technology has on reducing the price of capital accumulation in the future. ${ }^{10}$ The term $\frac{G_{t}}{Y_{t-1}}$ represents the externality from public capital in enhancing investment specific technological change in time period $t+1$. The aggregate capital-output ratio, $\frac{K_{t}}{Y_{t-1}}$, is also assumed to exert a positive externality effect on investment specific technological change. In particular, a higher aggregate stock of capital in $t, K_{t}$, relative to $Y_{t-1}$, raises $Z_{t+1}$. Like the externality from $n_{2}$, the planner internalizes the effect that stock of public capital and private capital has on investment specific technological change, while agents treat the effect of $\frac{G_{t}}{Y_{t-1}}$ and $\frac{K_{t}}{Y_{t-1}}$ on $Z_{t+1}-$ the bracketed term - as given. ${ }^{11}$

\footnotetext{
${ }^{10}$ This contrasts with Huffman (2008) where $\gamma=1$ is required for growth rates of $Z$ and output to be along the balanced growth path. We require $\gamma \in(0,1)$ for the equilibrium growth rate to adjust to the steady state balanced growth path.

${ }^{11}$ Assuming $\xi=0$ in (3) and $\gamma=1$, in equation (7) yields the setup in Huffman (2008).
} 


\subsection{The Planner's Problem}

We first solve the planner's problem. The aggregate resource constraint the economy faces in each time period $t$ is given by

$$
C_{t}+I_{t} \equiv Y_{t}(1-\tau)=\underline{A} K_{t}^{\alpha} n_{1 t}^{1-\alpha}\left(n_{2 t}^{1-\alpha}\right)^{\xi}(1-\tau)
$$

where agents consume $C_{t}$ at time period $t$ and invest $I_{t}$ at time period $t$. Aggregate consumption and investment add up to after-tax levels of output, $Y_{t}(1-\tau)$, in every time period.

The planner maximizes life-time utility of a representative agent - given by (1) - subject to the economy wide resource constraint given by (8), the laws of motion (4) and (5), the equation describing investment specific technological change (7), the identity for total supply of labor given by (2) and finally, the government budget constraint given by (6). ${ }^{12}$ This yields the first best fiscal policy in the model. ${ }^{13}$

\subsubsection{First Order Conditions}

The Lagrangian for the planner's problem is given by,

$$
L=\sum_{t=0}^{\infty} \beta^{t}\left[\log C_{t}+\log \left(1-n_{1 t}-n_{2 t}\right)+\lambda_{t}\left\{\underline{A} K_{t}^{\alpha} n_{1 t}^{1-\alpha}\left(n_{2 t}^{1-\alpha}\right)^{\xi}(1-\tau)-C_{t}-I_{t}\right\}\right]
$$

where $\lambda_{t}$ is the Lagrangian multiplier. We assume that $\delta=1$ for simplification.

The following first order conditions obtain with respect to $C_{t}, K_{t+1}, n_{1 t}$, and $n_{2 t}$, respectively ${ }^{14}$ :

$$
\begin{gathered}
\left\{C_{t}\right\}: \frac{1}{C_{t}}=\lambda_{t} \\
\left\{K_{t+1}\right\}: \frac{1}{C_{t} Z_{t}}=\frac{\alpha \beta Y_{t+1}(1-\tau)}{C_{t+1} K_{t+1}}+\beta^{2} \frac{I_{t+2}}{C_{t+2}} \frac{(1-\gamma)(1-\mu)}{K_{t+1}}+\frac{\beta^{3}(1-\gamma)(\gamma(1-\mu)-\alpha)}{K_{t+1}} \sum_{j=0}^{\infty} \beta^{j} \gamma^{j} \frac{I_{t+j+3}}{C_{t+j+3}} \\
\left\{n_{1 t}\right\}: \frac{1}{1-n_{t}}=\frac{(1-\alpha) Y_{t}(1-\tau)}{C_{t} n_{1 t}}-\frac{\beta^{2}(1-\alpha)(1-\gamma)}{n_{1 t}} \sum_{j=0}^{\infty} \beta^{j} \gamma^{j} \frac{I_{t+j+2}}{C_{t+j+2}}
\end{gathered}
$$

${ }^{12}$ Clearly, $C_{t}+I_{t}+I_{t}^{g}=Y_{t}$.

${ }^{13} \mathrm{We}$ do not solve for the Ramsey allocations (second best fiscal policy) in this paper.

${ }^{14}$ See Appendix A for derivations. 
and,

$$
\left\{n_{2 t}\right\}: \frac{1}{1-n_{t}}=\frac{(1-\alpha) \xi Y_{t}(1-\tau)}{C_{t} n_{2 t}}+\beta \theta \frac{I_{t+1}}{C_{t+1} n_{2 t}}+\frac{\beta^{2}(\gamma \theta-(1-\alpha) \xi(1-\gamma))}{n_{2 t}} \sum_{j=0}^{\infty} \beta^{j} \gamma^{j} \frac{I_{t+j+2}}{C_{t+j+2}}
$$

Equation (10) represents the standard first order condition for consumption, equating the marginal utility of consumption to the shadow price of wealth. Equation (11) is an augmented form of the standard Euler equation governing the consumption-savings decision of the household. The first term on the RHS of equation (11), $\frac{\alpha \beta Y_{t+1}(1-\tau)}{C_{t+1} K_{t+1}}$, corresponds to the

after tax marginal productivity of capital in $t+1$. The second term, $\frac{\beta^{2} I_{t+2}(1-\gamma)(1-\mu)}{C_{t+2} K_{t+1}}>0$, is the (further) increment to the marginal productivity of capital that agents get in period $t+2$ by postponing consumption today. This is increasing in the investment-consumption ratio, but adjusted by the weight, $1-\mu$, of the aggregate capital-output ratio, in the investment specific technological change equation. The third term, $\frac{\beta^{3}(1-\gamma)(\gamma(1-\mu)-\alpha)}{K_{t+1}} \sum_{j=0}^{\infty} \frac{\beta^{j} \gamma^{j} I_{t+j+3}}{C_{t+j+3}}$, is the discounted increase in marginal productivity of investing in capital from period $t+3$ onwards. This expression is adjusted by the term $(\gamma(1-\mu)-\alpha)$, which can be either positive or negative - depending on the relative importance of capital in equation (7) vis-a-vis its direct contribution to increasing output, from (3). It is easy to see that when $\gamma=1$, the additional terms in the Euler equation are equal to zero, yielding the standard Euler equation.

Equation (12) denotes the optimization condition with respect to labor supply $\left(n_{1 t}\right)$. Since $0<\gamma<1$, the second term in the RHS is positive which constitutes a reduction in the marginal utility of leisure. This reduces $n_{1}$ relative to the standard case in which there is no investment specific technological change. Similarly, in (13), the second and third terms in the RHS are the $t>0$ increment to marginal utility of leisure that accrues in the future because of $n_{2}$ 's role in assisting both research effort and increasing output. However, because $n_{2}$ has a direct and indirect effect (through production and investment specific technological change, respectively), the future discounted gains are adjusted by the term $[\gamma \theta-(1-\alpha) \xi(1-\gamma)]$. Going forward, it is important to note that if $[\gamma \theta-(1-\alpha) \xi(1-\gamma)]>0$, then final good production is not $n_{2}$ intensive.

\subsubsection{Decision Rules}

We now derive the closed form decision rules based on the above first order conditions using the method of undetermined coefficients, as shown the following Lemma (1).

Lemma $1 C_{t}, I_{t}, n_{t}, n_{1 t}, n_{2 t}$ are given by (14), (15), (16), where $0<\Phi<1$ is given by (17), 
and $0<x<1$ given by (18) is a constant.

$$
\begin{gathered}
C_{t}=\Phi_{P} Y_{t}(1-\tau), I_{t}=\left(1-\Phi_{P}\right) Y_{t}(1-\tau) \\
n_{t}=n_{P}=\frac{(1-\alpha)\left[(1-\beta \gamma)-\beta^{2}(1-\gamma)\left(1-\Phi_{P}\right)\right]}{(1-\alpha)\left[(1-\beta \gamma)-\beta^{2}(1-\gamma)\left(1-\Phi_{P}\right)\right]+\Phi_{P} x_{P}(1-\beta \gamma)} \\
n_{1 P}=x_{P} n_{P}, n_{2 P}=\left(1-x_{P}\right) n_{P}
\end{gathered}
$$

where $\Phi_{P}$ is given by

$$
\Phi_{P}=1-\frac{\alpha \beta(1-\beta \gamma)}{(1-\beta \gamma)-\beta^{2}(1-\gamma)(1-\mu)+\alpha \beta^{3}(1-\gamma)}
$$

and $x_{P}$ is given by

$$
x_{P}=\frac{(1-\alpha)\left\{(1-\beta \gamma)-\beta^{2}(1-\gamma)\left(1-\Phi_{P}\right)\right\}}{(1+\xi)(1-\alpha)\left\{(1-\beta \gamma)-\beta^{2}(1-\gamma)\left(1-\Phi_{P}\right)\right\}+\beta \theta\left(1-\Phi_{P}\right)} .
$$

Proof. See Appendix A for derivations.

While decision rules for consumption and investment given by (14) suggest that levels of consumption and investment would fall if the proportional tax rate $\tau$ increases, the share of after tax income spent on consumption given by $\Phi_{P}$ increases when $\mu$ rises, and thereby for investment it falls. Intuitively, when $\mu$ rises the weight on the ratio of public capital to output, $\frac{G_{t}}{Y_{t-1}}$ in augmenting investment specific technological change increases and so the weight on the ratio $\frac{K_{t}}{Y_{t-1}}$ falls. Since the planner solves the optimization problem for the representative agent, the effect of increases in $\mu$ on private investments is therefore expected.

When $\tau \neq \mu$, the allocations from the planner's problem are sub-optimal, even though there is balanced growth. The labor supply is affected by $\mu$. In fact, increases in $\mu$ has an ambiguous effect on $n_{1 P}$ but has a strong negative effect on $n_{2 P}$ which leads to an overall reduction in $n_{P}$.

An increase in $\mu$ increases the share of $n_{P}$ devoted to $n_{1 P}$, i.e., $\frac{\partial x_{P}}{\partial \mu}>0$. Since $\frac{\partial \Phi_{P}}{\partial \mu}>0$ from before, this implies $\frac{\partial n_{P}}{\partial \mu}<0 .{ }^{15}$ To see this, we can decompose the total change in $n_{P}$ because of changes in $\mu$ by

$$
\frac{\partial n_{P}}{\partial \mu}=\frac{\partial n_{1 P}}{\partial \mu}+\frac{\partial n_{2 P}}{\partial \mu}
$$

\footnotetext{
${ }^{15}$ See Appendix C
} 
Given $\frac{\partial x_{P}}{\partial \mu}>0$ and $\frac{\partial \Phi_{P}}{\partial \mu}>0$ (and hence, $\left.\frac{\partial\left(1-x_{P}\right)}{\partial \mu}<0\right) \frac{\partial n_{2 P}}{\partial \mu}<0$ will be true. Since the change in $n_{1 P}$ due to a change in $\mu$ can be written as

$$
\frac{\partial n_{1 P}}{\partial \mu}=x_{P} \underbrace{\frac{\partial n_{P}}{\partial \mu}}_{<0}+n_{P} \underbrace{\frac{\partial x_{P}}{\partial \mu}}_{>0},
$$

$\frac{\partial n_{1 P}}{\partial \mu}$ may or may not be negative. Hence, while an increase in $\mu$ has an ambiguous effect on $n_{1 P}$, it reduces $n_{2 P}$ and since the latter effect dominates, $n_{P}$ falls. This implies that an increased weight of public capital induces agents to supply lesser labor particularly towards research effort $\left(n_{2 P}\right)$.

\subsubsection{Balanced Growth Path}

We can easily obtain the balanced growth path (BGP) by substituting the above decision rules into the law of motion for investment specific technological progress, (7). Define $\widehat{M_{P}}$ a constant as

$$
\widehat{M_{P}}=B\left(\left(1-x_{P}\right) n_{P}\right)^{\theta}\left(1-\Phi_{P}\right)^{(1-\mu)(1-\gamma)} .
$$

Given the assumptions it is easy to show that we can obtain a constant growth rate for $Z$, $K, G$ and $Y$. This condition necessarily implies $0<\Phi_{P}, x_{P}, n_{P}<1$ which always holds true. We therefore have the following Lemma (2).

Lemma 2 On the steady state balanced growth path, the gross growth rate of $Z, K, G$ and $Y$ are given by (20), and (21) ${ }^{16}$

$$
\begin{gathered}
\widehat{g_{z_{P}}}=\left[\widehat{M_{P}}\left\{(\tau)^{\mu}(1-\tau)^{1-\mu}\right\}^{(1-\gamma)}\right]^{\frac{1}{2-\gamma}} \\
\widehat{g_{k_{P}}}=\widehat{g_{g_{P}}}=\widehat{g_{z_{P}}} \frac{1}{1-\alpha}, \widehat{g_{y_{P}}}={\widehat{g_{k_{P}}}}^{\alpha}={\widehat{g_{z_{P}}}}^{\frac{\alpha}{1-\alpha}} .
\end{gathered}
$$

There are several aspects of the equilibrium growth rate worth mentioning. First, the growth rate is independent of the technology parameter, $\underline{A}$, as in Huffman (2008). Second, the growth rate of output, $\widehat{g_{y_{P}}}$, is less than $\widehat{g_{k_{P}}}$ along the balanced growth path because equation (7) is homogenous of degree $1+\theta$. Lemma (2) therefore clearly establishes that the effect of the stock of public capital on $Z$ affects not just marginal productivity of factor inputs but also growth rate at the balanced growth path.

Finally, from expression (20), the tax rate exerts a positive effect on growth as well as a negative effect. This is similar to the equation characterizing the growth maximizing tax rate

\footnotetext{
${ }^{16}$ See Bishnu, Ghate and Gopalakrishnan (2011)
} 
in models with public capital. The mechanism here is however different. For small values of the tax rate, a rise in $\tau$ leads to higher public capital relative to output, $Y_{t-1}$. This raises the future value of investment specific technological change, $Z$. An increase in $Z$ reduces the real price of capital, stimulating investment and long run growth. However, for higher tax rates, further increases in the tax rate depresses after tax income, and investment. This reduces $G$ relative to $Y$, lowering $Z$, and depressing investment and long run growth. Hence, there is a unique growth maximizing tax rate.

Using the expression for $g_{z_{P}}$ in (20) we can characterize the growth maximizing tax rate as follows:

Proposition 1 In the steady state, the planner maximizes growth by choosing the proportional tax rate given by $\tau=\mu$.

Proof. See Appendix A.

Proposition (1) sets a benchmark for the planner to set the optimal tax rate. If the planner wants to maximize growth, he should set the tax rate to $\mu$. The higher the weight

attached to $\frac{G_{t}}{Y_{t-1}}$ in the investment specific technological change equation, the higher should be the optimal tax rate set by the planner. This result is intuitive since it suggests that the government would have to impose a higher tax rate on income if public capital were to play a greater role in driving investment specific technological change.

\subsubsection{Comparative Statics.}

Equation (20) suggests that the equilibrium growth rate can be decomposed into two sources - those coming from the term, $\widehat{M_{P}}$ which captures the effects on growth from $n_{P}, x_{P}$, and $\Phi_{P}$ (terms that are independent of the proportional tax rate $\tau$ ) and a composite (bracketed) term which captures the trade-offs of increasing the proportional tax:

$$
\widehat{g_{z_{P}}}=\left\{\widehat{M_{P}}\right\}^{\frac{1}{2-\gamma}} \underbrace{\left[\left\{(\tau)^{\mu}(1-\tau)^{1-\mu}\right\}^{(1-\gamma)}\right.}_{\text {The effects of growth from taxes }}]^{\frac{1}{2-\gamma}} .
$$

It is important to note that the characterization of optimal growth in the planning problem is identical to Barro (1990) as in Proposition (1). This is because along the balanced growth path, the growth rate is purely dependent on the growth rate of $Z_{t}$. But since public capital affects ISTC, it affects growth through the tax rate.

What happens to growth because of a change in the deep parameter $\mu$ ? In particular, we choose two values of $\mu=\{0.5,0.7\}$. Given the other parameter values, ${ }^{17}$

${ }^{17}$ The value of other parameters are as follows: $\alpha=0.35, \beta=0.95, \gamma=0.5, \delta=1, \theta=0.2, \xi=1$. These 
[Insert Figure 4]

Figure (4) shows that an increase in $\mu$ from 0.5 to 0.7 increases the growth maximizing tax rate, which is expected, as seen in proposition (1). The plot shifts upward and skews to the right because an increase in $\mu$ from 0.5 to 0.7 reduces the optimal allocation towards $n_{2}$ which leads to a reduction in the growth rate for initially lower values of $\tau$. However, for higher values of $\tau$ the contribution from $\frac{G_{t}}{Y_{t-1}}$ starts dominating and therefore, the growth rates are higher as compared to the growth rates for a lower value of $\mu .^{18}$

\subsection{The Competitive Decentralized Equilibrium}

We now solve the competitive decentralized equilibrium. Consider an economy that is populated by a set of homogenous and infinitely lived agents. There is no population growth and the representative firms are completely owned by agents, who supply labor for final goods production, $n_{1}$, and $\mathrm{R} \& \mathrm{D}, n_{2}$. Firms pay taxes (or receive subsidies) on capital income $\tau_{k} \in(-1,1)$ while agents pay taxes (or receive subsidies) on labor income $\tau_{n} \in(-1,1)$. Agents derive utility from consumption of the final good and leisure given in (1). The wage payment $w_{t}$ for both kinds of labor are the same since there is no skill difference assumed between both activities. Agents fund consumption and investment decisions from their after tax wages which they receive for supplying labor $n_{1}$ and $n_{2}$, and capital income earned earned from holding assets, which essentially equals the returns to capital lent out for production at each time period $t$.

The representative firm produces the final good based on (3) but takes the externality from $n_{2}$ (given by $\bar{n}_{2}$ ) as given. Hence, the production function is given by

$$
Y_{t}=\underbrace{A}_{\text {Externality }} \underbrace{\left(\bar{n}_{2}^{1-\alpha}\right)^{\xi}}_{t} K_{t}^{\alpha} n_{1 t}^{1-\alpha}
$$

where the law of motion of private capital is given by (4). What is different compared to (3) is that the agent takes the externality due to $n_{2}$ as given. As mentioned earlier, agents also treat the effect of $\frac{G_{t}}{Y_{t-1}}$ and $\frac{K_{t}}{Y_{t-1}}$ on $Z_{t+1}$ as given. The government funds public investment, $I_{t}^{g}$, at each time period $t$ using a distortionary tax imposed on labor, $\tau_{n} \in(-1,1)$, and capital, $\tau_{k} \in(-1,1)$ respectively. The following is therefore the government budget constraint:

$$
I_{t}^{g}=w_{t}\left(n_{1 t}+n_{2 t}\right) \tau_{n}+\left\{Y_{t}-w_{t}\left(n_{1 t}+n_{2 t}\right)\right\} \tau_{k} .
$$

parameter values are borrowed from Huffman (2008), except for $\xi=1$ which is the externality parameter due to $n_{2_{P}}$ in our framework. We also choose the value of $B=2$, which is the scaling parameter in $Z$.

${ }^{18}$ These results are however sensitive to level of persistence parameter $\gamma$. 
Like Huffman (2008), we assume that profits are taxed according to the same rate as capital income.

\subsubsection{The Firm's Dynamic Profit Maximization Problem}

Firms solve their dynamic profit maximization problems which, at time $t$, have capital stock, $K_{t}$, and $Z_{t}$. Let $v\left(K_{t}, Z_{t}\right)$ denote the value function of the firm at time $t$. The returns to investment in the credit markets are given by $r_{t}$ at time period $t$. The following is the firm's value function

$$
v\left(K_{t}, Z_{t}\right)=\max _{K_{t+1}, n_{1 t}, n_{2 t}}\left\{\left(Y_{t}-w_{1 t} n_{1 t}-w_{2 t} n_{2 t}\right)\left(1-\tau_{k}\right)-\frac{K_{t+1}}{Z_{t}}+\frac{1}{1+r_{t}} v\left(K_{t+1}, Z_{t+1}\right)\right\}
$$

which it maximizes subject to (5) and (7).

From the firm's maximization exercise yields the competitive factor prices for wages, and the return to capital., we get the following first order conditions, ${ }^{19}$

$$
\begin{gathered}
\left\{K_{t+1}\right\}: \frac{1}{Z_{t}}=\left(\frac{1}{1+r}\right) \frac{\alpha Y_{t+1}\left(1-\tau_{k}\right)}{K_{t+1}} \\
\left\{n_{1 t}\right\}: w_{t}=\frac{(1-\alpha) Y_{t}}{n_{1 t}} \\
\left\{n_{2 t}\right\}: w_{t}\left(1-\tau_{k}\right)=\left(\frac{\theta}{1+r_{t}}\right)\left(\frac{1}{n_{2 t}}\right) \sum_{j=0}^{\infty}\left(\frac{\gamma}{1+r}\right)^{j} I_{t+j+1} .
\end{gathered}
$$

In deriving these factor prices, we assume that the externality from $n_{2}$ in production is assumed to be given.

\subsubsection{The Agents Problem}

Agents are allowed to borrow and lend by participating in the credit market. A representative agent maximizes (1) subject to the consumer budget constraint,

$$
a_{t+1}=\left(1+r_{t}\right) a_{t}+w_{t}\left(n_{1 t}+n_{2 t}\right)\left(1-\tau_{n}\right)-c_{t}
$$

the laws of motion given by (4), (5) and (7), total labor supply given by (2), and takes factor prices and profits as given. Agents therefore hold assets $a_{t}$ which in equilibrium equals

\footnotetext{
${ }^{19}$ See Appendix B.
} 
private capital accumulation used in production, as follows

$$
a_{t}=K_{t}, \forall t \geq 0
$$

\subsubsection{First Order Conditions}

The following is the Lagrangian for the agent.

$$
L=\sum_{t=0}^{\infty} \beta^{t}\left[\log C_{t}+\log \left(1-n_{1 t}-n_{2 t}\right)+\lambda_{t}\left\{\left(1+r_{t}\right) a_{t}+w_{t}\left(n_{1 t}+n_{2 t}\right)\left(1-\tau_{n}\right)-c_{t}-a_{t+1}\right\}\right]
$$

The optimization conditions with respect to $C_{t}, K_{t+1}, n_{1 t}$, and $n_{2 t}$, are given by equations (25), (26), (27) and (28) respectively:

$$
\begin{gathered}
\left\{C_{t}\right\}: \frac{1}{C_{t}}=\lambda_{t} \\
\left\{a_{t+1}\right\}: \frac{\beta\left(1+r_{t}\right)}{c_{t+1}}=\frac{1}{c_{t}} \\
\left\{n_{1 t}\right\}: \frac{w_{t}\left(1-\tau_{n}\right)}{c_{t}}=\frac{1}{1-n_{t}} \\
\left\{n_{2 t}\right\}: \frac{w_{t}\left(1-\tau_{n}\right)}{c_{t}}=\frac{1}{1-n_{t}} .
\end{gathered}
$$

Once we substitute for factor prices from the firm's problem into the above first order conditions, we obtain the following first order conditions for the competitive equilibrium:

$$
\begin{gathered}
\left\{K_{t+1}\right\}: \frac{1}{c_{t} Z_{t}}=\frac{\alpha \beta Y_{t+1}\left(1-\tau_{k}\right)}{c_{t+1} K_{t+1}} \\
\left\{n_{1 t}\right\}: \frac{1}{1-n_{t}}=\frac{(1-\alpha) Y_{t}\left(1-\tau_{n}\right)}{c_{t} n_{1 t}} \\
\left\{n_{2 t}\right\}: \frac{1}{1-n_{t}}=\left(\frac{\beta \theta}{n_{2 t}}\right)\left(\frac{1-\tau_{n}}{1-\tau_{k}}\right) \sum_{j=0}^{\infty} \beta^{j} \gamma^{j} \frac{I_{t+j+1}}{c_{t+j+1}} .
\end{gathered}
$$

Equation (29) is the standard Euler equation for the household. Equations (30) and (31) equate the after tax wage to the MRS between consumption and leisure. 


\subsubsection{Decision Rules}

Based on the above first order conditions, the following Lemma (3) states the optimal decision rules for the agents.

Lemma $3 C_{t}, I_{t}, n_{t}, n_{1 t}, n_{2 t}$ are given by (32), (33), (34), where $0<\Phi<1$ is given by (35), and $0<x<1$ given by (36) is a constant.

$$
\begin{gathered}
C_{t}=\Phi_{C E} A Y_{t}, I_{t}=\left(1-\Phi_{C E}\right) A Y_{t} \\
\text { where, } A=\alpha\left(1-\tau_{k}\right)+(1-\alpha)\left(1-\tau_{n}\right)-\frac{\alpha \beta^{2} \theta\left(\tau_{n}-\tau_{k}\right)}{(1-\beta \gamma)} \\
n_{t}=n_{C E}=\frac{(1-\alpha)\left(1-\tau_{n}\right)}{(1-\alpha)\left(1-\tau_{n}\right)+x_{C E} \Phi_{C E} A}, \\
n_{1 C E}=x_{C E} n_{C E}, n_{2 C E}=\left(1-x_{C E}\right) n_{C E},
\end{gathered}
$$

where $\Phi_{C E}$ is given by

$$
\Phi_{C E}=1-\frac{\alpha \beta\left(1-\tau_{k}\right)}{A}
$$

and $x_{C E}$ is given by

$$
x_{C E}=\frac{(1-\alpha)(1-\beta \gamma)}{\alpha \beta^{2} \theta+(1-\alpha)(1-\beta \gamma)} .
$$

Proof. See Appendix B for details.

The above decision rules imply that depending upon the parameter values, there exists a feasible range of values that $\tau_{k}$ and $\tau_{n}$ can take such that

$$
0<A, \Phi_{C E}, n_{C E}<1
$$

are true. The relationship between growth rates at the balanced growth path for private capital, public capital, output and investment specific technological change are identical to that for the planner's version, as given in Lemma (2).

\subsection{Decentralizing the Planner's Growth Rate}

We would like to ascertain under what conditions the competitive equilibrium allocations yield the planner's growth rate. We consider two cases: the case in which planner imposes equal factor income taxes on agents, i.e., $\tau_{n}=\tau_{k}=\tau$, and the case under which factor income taxes are unequal $\tau_{n} \neq \tau_{k}$. 


\subsubsection{Equal factor income taxes:}

No externalities Suppose there are no externalities in the model, i.e., $\gamma=1$ and as $\xi=0$. Further, the government imposes equal factor income taxes on both capital and labor income, such that

$$
\tau_{n}=\tau_{k}=\tau
$$

We show in Appendix C that equal factor income taxes will always decentralize the planner's growth rate. In general in the absence of the externalities, $\tau_{k}=\tau_{n}=\tau$, is the only factor income tax combination that decentralizes planner's growth. However, when $\left(\frac{1-\beta}{\beta}\right)^{2}=\theta$, any factor income tax combination (including the case of equal factor income taxes) also decentralizes the planner's growth rate. Hence, in this case there is indeterminacy.

Externalities In this case (when $0<\gamma<1$ and $\xi>0$ ), the decision rules for the competitive equilibrium at optimum. $C_{t}, I_{t}, n_{t}, n_{1 t}, n_{2 t}$ are now given by (37), (38), (39), where $0<\Phi_{C E}<1$ is given by (40), and $0<x_{C E}<1$ given by (41) is a constant.

$$
\begin{gathered}
C_{t}=\Phi_{C E} A Y_{t}, I_{t}=\left(1-\Phi_{C E}\right) A Y_{t} \\
\text { where, } A=(1-\tau) \\
n_{t}=n_{C E}=\frac{(1-\alpha)}{(1-\alpha)+x_{C E} \Phi_{C E}}
\end{gathered}
$$

where $\Phi_{C E}$ is given by

$$
\Phi_{C E}=1-\alpha \beta
$$

and $x_{C E}$ is given by

$$
x_{C E}=\frac{(1-\alpha)(1-\beta \gamma)}{\alpha \beta^{2} \theta+(1-\alpha)(1-\beta \gamma)} .
$$

When factor income taxes are equal, growth rates in the competitive environment is maximized when $\tau=\mu .{ }^{20}$ However, since agents do not internalize the externality in both production and investment specific technological change, in Appendix $\mathrm{C}$ we show that the competitive equilibrium growth rate may not be equal to the planner's growth rate. However, as the level of persistence, $\gamma$ (the coefficient on $Z$ ), in investment specific technological change increases, and as the externality in production due to the choice $n_{2 C E}$ decreases (i.e., the effect of all three externalities diminish) the decision rules for the agent coincide with that of the planner and hence growth rates coincide. We summarize this in terms of the following

\footnotetext{
${ }^{20}$ The proof of this is similar to the proof of Proposition (1) which can be refered to in Appendix A.
} 
proposition:

Proposition 2 While equal factor income taxation restores the planner's growth rate when there are no externalities, in the presence of externalities, equal factor income taxes may not yield the planner's growth rate.

Proof. See Appendix C.

Empirically factor income tax equality is rarely observed. There are two aspects that should be noted. As shown in Figure (2) similarly growing economies factor income taxes are not just unequal, but the absolute gaps between the two also vary. As shown in Figure (3), there is no clear ranking between the two level of factor income tax rates. By incorporating different production externalities in a model of endogenous investment specific technological change, our results show that different parametric values for these externalities can help explain factor income tax gaps that we observe in actual economies.

\subsubsection{Unequal factor income taxes}

We calibrate the factor income tax gaps in the presence of externalities assuming that the planner taxes factor incomes at different rates. We show numerically that there will be indeterminacy. In other words, there will exist multiple factor income tax combinations that decentralize the planner's growth rate. ${ }^{21}$ The cases below show that the nature and magnitude of the externality influences the optimal factor income tax mix.

To see this, we set different (and arbitrary) levels of the externality due to $n_{2 C E}$ in production $(\xi)$. We keep $\tau_{n}$ fixed and then derive the value of $\tau_{k}$ that decentralizes planner's efficient growth rates for changes in $\xi$. We repeat this experiment for different values of $\gamma$ (high $=0.8$, low $=0.4$, equal to 1 ), fixing the values of $\mu$ and $\theta$ to reasonable guesses. We also choose the value of $B=2$ although this is just a scaling parameter which can easily be changed.

Case 1: $\gamma=0.8 ; \mu=0.2 ; \theta=0.5$. As seen in Figure (5), $\tau_{k}$ is high, but as $\xi$ falls, $\tau_{k}$ increases gradually. This happens because the effect of $n_{2 C E}$ on ISTC is high $(\theta=0.5)$. Households choose to accumulate more capital. The planner therefore sets a higher tax on capital to restore the planning growth rate relative to the case where $\gamma$ is low (Case 2).

\section{[Insert Figure 5]}

\footnotetext{
${ }^{21}$ The Matlab programs for all results in this paper are available from the authors on request.
} 
Case 2: $\gamma=0.4 ; \mu=0.2 ; \theta=0.5$. In this case, as shown in Figure (6) the optimal tax on capital income is a subsidy When $\gamma$ is low (0.4), the externality term is high: this implies that agents, compared to the previous case, are not internalizing the role of public and private capital aggregates have on ISTC. Agents therefore under-invest in capital, and the planner can restore the equilibrium growth rate by subsidizing capital income. Note that Case 1 and Case 2 are directly comparable because we are fixing $\mu$ and $\theta$ across two arbitrary values of $\gamma$.

\section{[Insert Figure 6]}

Case 3: $\gamma=1 ; \mu=0.2 ; \theta=0.5$. As $\xi$ falls, $\tau_{k} \rightarrow \tau_{n}$. And as shown in Figure (7), the externality from aggregate public and private capital is inoperative. Hence, as the externality from $n_{2 C E}$ falls (and also becomes inoperative), the planner can restore the planning growth rate only by taxing both factor incomes equally. This is shown in the case with equal factor income taxes.

\section{[Insert Figure 7]}

In the above cases, as we can see, the tax on capital income is lower than the tax on labor income. However, it can be shown that getting a higher tax on capital income than a tax on labor income is also a possibility in our framework when $\alpha$ is high.

Case 4: $\gamma=0.4 ; \mu=0.6 ; \theta=0.5 ; \alpha=0.7$. We show that there is some parameter combinations in which $\tau_{k}>\tau_{n}$. We choose a value of $\alpha$ at 0.7 and we fix the value of $\tau_{n}$ at 0.4. When $\xi$ is lowered from 1 to 0 gradually, $\tau_{k}$ exceeds $\tau_{n}$. This is shown in Figure (8).

\section{[Insert Figure 8]}

In sum, there exist parameter combinations under which the ranking on factor income tax levels can get reversed. This accords with the empirical observations in Figure (3) which shows that countries with similar growth rates, can have widely varying factor income tax combinations.

Discussion Our general result is that both factor income tax combinations converge towards equality as the magnitude of externalities diminish. For instance, in Figure (9) we fix the value of $\xi=1$. We set $\alpha=0.35$ and $\theta=0.2$. We vary the value of $\gamma$ from low values of 0.3 to 1 . 


\section{[Insert Figure 9]}

Figure (9) shows that for a given level of $\xi$, as the value of $\gamma \longrightarrow 1$, the first best locus for $\left(\tau_{n}, \tau_{k}\right)$ shifts up and closer towards the $45^{\circ}$ line from below. This means for a given $\tau_{n}$, $\tau_{k}$ increases and both taxes converge towards equality.

\section{[Insert Figure 10]}

Figure (10) looks at the case for $\xi=0$, that is, the case where there is no externality from $n_{2}$ affecting final goods production. We fix the value of $\gamma$ and we vary the values of $\xi$ from 1 to 0 .Our results are similar: both factor income taxes converge to the $45^{\circ}$ line. ${ }^{22}$

\subsection{Welfare}

How does the first best factor income tax combination compare with the welfare maximizing tax rates ? Our result - which we show numerically - is that different magnitudes of the key externality parameters $-\gamma$ and $\xi$-influence the welfare maximizing factor income tax combinations.

We compute welfare for agents by substituting the representative agent's optimal decision rules given in Lemma (3) and given by (32), (33), (34), (35), and (36) into the representative agent's discounted life time utility function given by (1). This yields the following expression $^{23}$

$$
\Lambda=\frac{\log \left[\Phi_{C E}\right]}{1-\beta}+\frac{\log \left[Y_{0}\right]}{1-\beta}+\frac{\log \left[A\left(\tau_{k}, \tau_{n}\right)\right]}{1-\beta}+\frac{\beta^{2} \alpha}{(1-\beta)(1-\alpha)} \log g_{c, C E}+\frac{\log \left(1-n_{C E}\right)}{1-\beta} .
$$

Figures (11) and (12) show how maximum welfare gets affected for different values of $\gamma$ and $\xi$. Figure (11) shows that the maximum welfare level increases as the externality due to public capital and private capital in $Z$ diminishes. The locus of maximum welfare for different values of $\gamma$ gradually shifts up as $\xi$ is gradually brought down to 0 .

\section{[Insert Figure 11]}

Figure (12) replicates the above exercise by assuming $\gamma$ as the shifting parameter and $\xi$ as the changing parameter.

\section{[Insert Figure 12]}

\footnotetext{
${ }^{22}$ All cases were computed in Matlab. These are available from the authors on request.

${ }^{23}$ See Appendix D
} 


\subsubsection{Pareto Ranking of Tax Rates: Some Examples}

What are the welfare implications of first best factor income tax combinations that restore planner's growth? We conduct the following numerical experiment for two extreme values of $\gamma$ and $\xi$. We assume $\gamma$ takes arbitrary values $\{0.3,0.9\}$ that is, a high externality and low externality case; meanwhile, $\xi$ takes values $\{0,1\}$, which is the no externality versus high externality case.

Figure (13) plots the first best tax locus when there is no externality due to $n_{2}$ in production $(\xi=0)$. This locus represents all factor income tax combinations that restores the planner's growth rate. The welfare maximizing tax combination - which is unique - is indicated by the circle in Figure (14), which is underneath the first best tax locus. This means that for the welfare maximizing tax to replicate the first best allocation, the tax on capital income needs to be higher. The result is similar when we have higher values of $\gamma$.

\section{[Insert Figure 13]}

In Figure (13) we now assume that there is a high externality in production $(\xi=1)$. When $\gamma$ takes on a low value, the locus of first best tax combinations is distinctly below the unique welfare maximizing tax rate. This changes when $\gamma$ is high. As can be seen in Figure (13) and Figure (14), the welfare maximizing tax on capital income is always less than the labor income tax rate. ${ }^{24}$ This is consistent qualitatively with the experience of a majority of the countries depicted in Figure (2). Intuitively, because of strong production externalities, there is under-accumulation of capital. Therefore, in order to get the planner to obtain the first best tax mix, the tax on capital income needs to be low.

We generalize these results in terms of the following remark which decomposes the source of divergence between the welfare maximizing tax combination from the first best tax policy in terms of exogenous ISTC and endogenous ISTC.

Remark 1 When the growth of investment specific technological change, $g_{Z}$, is exogenous $(\xi=0, \gamma=1, \theta=0)$ the unique welfare maximizing tax can replicate the first best tax policy. When investment specific technological change is endogenous $(\xi \geqq 0, \gamma \leqq 1, \theta \neq 0)$, then the first best tax policy never maximizes welfare. Therefore, both production externalities and endogenous ISTC imply departures from the first best policy.

The above remark suggests that the departure of the welfare maximizing tax rate from the first best tax policy can be decomposed into 1) the effect because of externalities, and 2)

\footnotetext{
${ }^{24}$ Even in the left panel of Figure (14) when $\gamma$ takes on a low value, the locus of first best tax combinations is distinctly below the unique welfare maximizing tax rate. When we impose factor income taxes to be the same, it can be easily shown that the welfare maximizing tax rate will be less than $\mu$.
} 
the effect because of $n_{2}$. When production externalities are absent, and ISTC is endogenous $(\theta \neq 0)$, the welfare maximizing tax mix doesn't replicate the first best fiscal policy. The lower tax on capital income relative to the first best tax on capital income obtained in this case is because of the role that endogenous ISTC has on capital accumulation. With the additional restriction that $\theta=0$, ISTC becomes exogenous, and the welfare maximizing tax mix coincides with the first best policy. Therefore, both production externalities and endogenous ISTC imply departures from the first best policy.

\section{[Insert Figure 14]}

\section{Conclusion}

This paper constructs a tractable endogenous growth model with production externalities in which the stock of public capital influences investment specific technological change. The externalities appear through both public and private capital and labor. The focus of our paper is on endogenous growth. Our model is motivated by the empirical observation that advanced economies experiencing similar or identical growth rates have widely varying factor income tax combinations.

We characterize the first best fiscal policy in the model: i.e., the growth maximizing tax rates in the planner's problem and the decentralized equilibrium. Solving the decentralized competitive equilibrium, we show that there is an indeterminate combination of capital tax rates and the labor tax rates that can replicate the first-best allocation. In particular, we highlight the role that such externalities have in determining the first best fiscal policy. Our framework allows also us to Pareto rank the first best fiscal policy. We numerically show that the departure of the welfare maximizing tax rate from the first best tax policy can be decomposed into 1) the effect because of externalities, and 2) the effect because due to $n_{2}$. Therefore, both production externalities and endogenous ISTC imply departures from the first best policy.

While we do not solve for the Ramsey allocations (second best fiscal policy), our results are closely related to a celebrated literature started by Judd (1985) and Chamley (1986) who find that capital taxation decreases welfare and a zero capital tax is thus efficient in the long-run steady state. From a growth standpoint, models analyzing the equilibrium relationship between capital income taxes and growth also typically find that an increase of the capital income tax reduces the return to private investment, which in turn implies a decrease of capital accumulation and thus growth (see Lucas (1990) and Rebelo (1991)). In contrast, our results are consistent with some other papers in this literature which show that 
the optimal capital income tax is positive, i.e., high capital income taxation may restore the planner's growth rate (see Uhlig and Yanagawa (1996) and Rivas (2003)).

In terms of future work, one could formalize the second best Ramsey policy within our environment. 


\section{References}

[1] Barro, Robert J, October 1990. Government Spending in a Simple Model of Endogenous Growth, Journal of Political Economy, Vol. 98(5), pages S103-26.

[2] Bishnu, Monisankar \& Ghate, Chetan \& Gopalakrishnan, Pawan, 2011. Distortionary Taxes and Public Investment in a Model of Endogenous Investment Specific Technological Change, MPRA Paper 34111, University Library of Munich, Germany, revised 18 April 2012.

[3] Chamley, C., 1986. Optimal taxation of capital income in general equilibrium with infinite lives. Econometrica Vol. 54(3), pages 607-622.

[4] Chen, Been-Lon, 2006. Public Capital, endogenous growth, and endogenous fluctuations, Journal of Macroeconomics, Vol. 28(4), pages 768-774.

[5] Davidson, Adam, November 20, 2012. Skills Don’t Pay the Bills, The New York Times.

[6] Eicher, Theo and Turnovsky, Stephen J., August 2000. Scale, Congestion and Growth, Economica, New Series, Vol. 67(267), pages 325-346.

[7] Fisher, Walter H and Turnovsky, Stephen J., 1997. Congestion and Public Capital. Economics Series 47, Institute for Advanced Studies.

[8] Fisher, Walter H and Turnovsky, Stephen J., 1998. Public Investment, Congestion, and Private Capital Accumulation. The Economic Journal 47, Vol. (108), No. 447, pages 399-413.

[9] Futagami, Koichi, Morita, Yuichi and Shibata, Akihisa, December 1993. Dynamic Analysis of an Endogenous Growth Model with Public Capital, Scandinavian Journal of Economics, Vol. 95(4), pages 607-25.

[10] Greenwood, Jeremy, Hercowitz, Zvi and Krusell, Per, June 1997. Long-run implications of Investment-Specific Technological Change, American Economic Review, Vol. 87(3), pages 342-362.

[11] Greenwood, Jeremy, Hercowitz, Zvi and Krusell, Per, 2000. The Role of InvestmentSpecific Technological Change in the business cycle, European Economic Review, Vol. 44 (1), pages 91-115. 
[12] Gort, Michael, and Jeremy Greenwood \& Peter Rupert, January 1999. Measuring the Rate of Technological Progress in Structures, Review of Economic Dynamics, Vol. 2(1), pages 207-230.

[13] Huffman, G.W., August 2004. Propagation through endogenous investment-specific technological change, Economics Letters, Vol. 84(2), pages 191-197.

[14] Huffman, G.W., 2007. Endogenous growth through investment-specific technological change, Review of Economic Dynamics, Vol. 10(4), 615-645.

[15] Huffman, G.W., 2008. An analysis of fiscal policy with endogenous investment-specific technological change, Journal of Economic Dynamics and Control, Vol. 32(11), pages 3441-3458.

[16] Judd, Kenneth L., October 1985. Redistributive taxation in a simple perfect foresight model, Journal of Public Economics, Vol. 28(1), pages 59-83.

[17] Krusell, Per, June 1998. Investment-Specific R\&D and the Decline in the Relative Price of Capital, Journal of Economic Growth, Vol. 3(2), pages 131-41.

[18] Lucas, Robert E, Jr, April 1990. Supply-Side Economics: An Analytical Review, Oxford Economic Papers, Oxford University Press, Vol. 42(2), pages 293-316.

[19] Mendoza, Enrique G., Razin, Assaf and Tesar, Linda L., December 1994. Effective tax rates in macroeconomics: Cross-country estimates of tax rates on factor incomes and consumption, Journal of Monetary Economics, vol. 34(3), pages 297-323.

[20] OECD (2012), Gross domestic product in US dollars, Economics: Key Tables from OECD, No. 5.doi: 10.1787/gdp-cusd-table-2012-10-en

[21] Ott, Ingrid and Turnovsky, Stephen J, 2006. Excludable and Non-Excludable Public Inputs: Consequences for Economic Growth, Economica, Vol. 73 (292), pages 725-748, November.

[22] Rebelo, Sergio, June 1991. Long-Run Policy Analysis and Long-Run Growth, Journal of Political Economy, Vol. 99(3), pages 500-521.

[23] Reis, Catarina, June 2011. Entrepreneurial Labor And Capital Taxation, Macroeconomic Dynamics, Cambridge University Press, Vol. 15(03), pages 326-335.

[24] Rivas, Luis A., June 2003. Income taxes, spending composition and long-run growth, European Economic Review, Vol. 47(3), pages 477-503. 
[25] Trabandt, Mathias and Uhlig, Harald 2009. How Far Are We From The Slippery Slope? The Laffer Curve Revisited, NBER Working Papers 15343.

[26] Uhlig, Harald \& Yanagawa, Noriyuki, November 1996. Increasing the capital income tax may lead to faster growth, European Economic Review, Vol. 40(8), pages 1521-1540.

[27] Whelan, Karl, 2003. A Two-Sector Approach to Modeling U.S. NIPA Data, Journal of Money, Credit and Banking, Blackwell Publishing, Vol. 35(4), pages 627-56, August. 


\section{Technical Appendix}

\section{Appendix A: The Planner's Version}

$$
\begin{gathered}
\left\{C_{t}\right\}: \frac{1}{C_{t}}=\lambda_{t}, \\
\left\{K_{t+1}\right\}: \frac{-\lambda_{t}}{Z_{t}}+\beta \lambda_{t+1} \frac{\alpha Y_{t+1}(1-\tau)}{K_{t+1}}-\beta \lambda_{t+1} \frac{\partial}{\partial K_{t+1}}\left(\frac{K_{t+2}}{Z_{t+1}}\right)-\beta^{2} \lambda_{t+2} \frac{\partial}{\partial K_{t+1}}\left(\frac{K_{t+3}}{Z_{t+2}}\right)-\ldots=0 . \\
\Rightarrow \frac{1}{C_{t} Z_{t}}=\frac{\alpha \beta Y_{t+1}(1-\tau)}{C_{t+1} K_{t+1}}+\frac{\beta}{C_{t+1}} \frac{K_{t+2}}{Z_{t+1}^{2}} \frac{\partial Z_{t+1}}{\partial K_{t+1}}+\frac{\beta^{2}}{C_{t+2}} \frac{K_{t+3}}{Z_{t+2}^{2}} \frac{\partial Z_{t+2}}{\partial K_{t+1}}+\ldots
\end{gathered}
$$

where,

$$
\begin{gathered}
\frac{\partial Z_{t}}{\partial K_{t+1}}=\frac{\partial Z_{t+1}}{\partial K_{t+1}}=0, \frac{\partial Z_{t+2}}{\partial K_{t+1}}=(1-\gamma)(1-\mu) \frac{Z_{t+2}}{K_{t+1}}, \frac{\partial Z_{t+3}}{\partial K_{t+1}}=\frac{\gamma Z_{t+3}}{Z_{t+2}} \frac{\partial Z_{t+2}}{\partial K_{t+1}}-\alpha(1-\gamma) \frac{Z_{t+3}}{K_{t+1}} \\
\Rightarrow \frac{\partial Z_{t+3}}{\partial K_{t+1}}=(1-\gamma) \frac{Z_{t+3}}{K_{t+1}}(\gamma(1-\mu)-\alpha) . \\
\Rightarrow \frac{\partial Z_{t+3+j}}{\partial K_{t+1}}=\gamma^{j}(1-\gamma) \frac{Z_{t+3+j}}{K_{t+1}}[\gamma(1-\mu)-\alpha], \text { for } j \geqq 0 .
\end{gathered}
$$

Hence,

$$
\left\{K_{t+1}\right\}: \frac{1}{C_{t} Z_{t}}=\frac{\alpha \beta Y_{t+1}(1-\tau)}{C_{t+1} K_{t+1}}+\beta^{2} \frac{I_{t+2}}{C_{t+2}} \frac{(1-\gamma)(1-\mu)}{K_{t+1}}+\frac{\beta^{3}(1-\gamma)(\gamma(1-\mu)-\alpha)}{K_{t+1}} \sum_{j=0}^{\infty} \beta^{j} \gamma^{j} \frac{I_{t+j+3}}{C_{t+j+3}}
$$

The FOC with respect to $n_{1 t}$ is as follows.

$$
\left\{n_{1 t}\right\}: \frac{-1}{1-n_{t}}+\frac{\lambda_{t}(1-\alpha) Y_{t}(1-\tau)}{n_{1 t}}-\lambda_{t} \frac{\partial}{\partial n_{1 t}}\left(\frac{K_{t+1}}{Z_{t}}\right)-\beta \lambda_{t+1} \frac{\partial}{\partial n_{1 t}}\left(\frac{K_{t+2}}{Z_{t+1}}\right)-\beta^{2} \lambda_{t+2} \frac{\partial}{\partial n_{1 t}}\left(\frac{K_{t+3}}{Z_{t+2}}\right)-\ldots=0
$$

where

$$
\frac{\partial Z_{t}}{\partial n_{1 t}}=\frac{\partial Z_{t+1}}{\partial n_{1 t}}=0, \frac{\partial Z_{t+2}}{\partial n_{1 t}}=-(1-\gamma)(1-\alpha) \frac{Z_{t+2}}{n_{1 t}}, \frac{\partial Z_{t+3}}{\partial n_{1 t}}=\frac{\gamma Z_{t+3}}{Z_{t+2}} \frac{\partial Z_{t+2}}{\partial n_{1 t}} \text { and so on. }
$$

Hence,

$$
\left\{n_{1 t}\right\}: \frac{1}{1-n_{t}}=\frac{(1-\alpha) Y_{t}(1-\tau)}{C_{t} n_{1 t}}-\frac{\beta^{2}(1-\alpha)(1-\gamma)}{n_{1 t}} \sum_{j=0}^{\infty} \beta^{j} \gamma^{j} \frac{I_{t+j+2}}{C_{t+j+2}}
$$


Similarly, the FOC with respect to $n_{2 t}$ is given by

$$
\left\{n_{2 t}\right\}: \frac{-1}{1-n_{t}}+\frac{\lambda_{t}(1-\alpha) \xi Y_{t}(1-\tau)}{n_{2 t}}-\lambda_{t} \frac{\partial}{\partial n_{2 t}}\left(\frac{K_{t+1}}{Z_{t}}\right)-\beta \lambda_{t+1} \frac{\partial}{\partial n_{2 t}}\left(\frac{K_{t+2}}{Z_{t+1}}\right)-\beta^{2} \lambda_{t+2} \frac{\partial}{\partial n_{2 t}}\left(\frac{K_{t+3}}{Z_{t+2}}\right) \ldots=0
$$

where,

$$
\begin{gathered}
\frac{\partial Z_{t}}{\partial n_{2 t}}=0, \frac{\partial Z_{t+1}}{\partial n_{2 t}}=\frac{\theta Z_{t+1}}{n_{2 t}} \\
\frac{\partial Z_{t+2}}{\partial n_{2 t}}=\frac{\gamma Z_{t+2}}{Z_{t+1}} \frac{\theta Z_{t+1}}{n_{2 t}}-(1-\alpha) \xi(1-\gamma) \frac{Z_{t+2}}{n_{2 t}} \\
\Rightarrow \frac{\partial Z_{t+2}}{\partial n_{2 t}}=(\gamma \theta-(1-\alpha) \xi(1-\gamma)) \frac{Z_{t+2}}{n_{2 t}} . \\
\Rightarrow \frac{\partial Z_{t+j+2}}{\partial n_{2 t}}=\gamma^{j}(\gamma \theta-(1-\alpha) \xi(1-\gamma)) \frac{Z_{t+j+2}}{n_{2 t}}, \text { for } j \geqq 0 .
\end{gathered}
$$

Hence,

$$
\left\{n_{2 t}\right\}: \frac{1}{1-n_{t}}=\frac{(1-\alpha) \xi Y_{t}(1-\tau)}{C_{t} n_{2 t}}+\beta \theta \frac{I_{t+1}}{C_{t+1} n_{2 t}}+\frac{\beta^{2}(\gamma \theta-(1-\alpha) \xi(1-\gamma))}{n_{2 t}} \sum_{j=0}^{\infty} \beta^{j} \gamma^{j} \frac{I_{t+j+2}}{C_{t+j+2}} .
$$

\section{The Decision Rules}

We use the method of undetermined coefficients to solve out for the decision rules.

$$
\begin{aligned}
& C_{t}=\Phi_{P} Y_{t}(1-\tau), \\
& I_{t}=\left(1-\Phi_{P}\right) Y_{t}(1-\tau) \\
& n_{1}=x_{P} n_{P} \\
& n_{2}=\left(1-x_{P}\right) n_{P} \\
& n_{t}=\bar{n} . \\
&\left\{K_{t+1}\right\}: \frac{1}{C_{t} Z_{t}}=\frac{\alpha \beta Y_{t+1}(1-\tau)}{C_{t+1} K_{t+1}}+\beta^{2} \frac{I_{t+2}}{C_{t+2}} \frac{(1-\gamma)(1-\mu)}{K_{t+1}}+\frac{\beta^{3}(1-\gamma)(\gamma(1-\mu)-\alpha)}{K_{t+1}} \sum_{j=0}^{\infty} \beta^{j} \gamma^{j} \frac{I_{t+j+3}}{C_{t+j+3}}
\end{aligned}
$$


This implies,

$$
\begin{gathered}
\Rightarrow \quad \frac{1}{\Phi_{P} Y_{t}(1-\tau) Z_{t}}=\beta \frac{\alpha Y_{t+1}(1-\tau)}{\Phi_{P} Y_{t+1}(1-\tau)\left(1-\Phi_{P}\right) Y_{t}(1-\tau) Z_{t}}+\beta^{2} \frac{\left(1-\Phi_{P}\right)}{\Phi_{P}\left(1-\Phi_{P}\right) Y_{t}(1-\tau) Z_{t}}(1-\gamma)(1-\mu) \\
+\frac{\beta^{3}(1-\gamma)(\gamma(1-\mu)-\alpha)}{\left(1-\Phi_{P}\right) Y_{t}(1-\tau) Z_{t}}\left(\frac{1}{1-\beta \gamma}\right) \frac{\left(1-\Phi_{P}\right)}{\Phi_{P}} \\
\Rightarrow\left(1-\Phi_{P}\right)=\frac{\alpha \beta(1-\beta \gamma)}{(1-\beta \gamma)\left[1-\beta^{2}(1-\gamma)(1-\mu)\right]-\beta^{3}(1-\gamma)[\gamma(1-\mu)-\alpha]} .
\end{gathered}
$$

From the FOC for $n_{1 t}$,

$$
\begin{gathered}
\frac{n_{P}}{1-n_{P}}=\frac{(1-\alpha)}{\Phi_{P} x_{P}}-\frac{\beta^{2}(1-\alpha)(1-\gamma)\left(1-\Phi_{P}\right)}{x_{P}(1-\beta \gamma) \Phi_{P}} \\
\Rightarrow n_{P}=\frac{(1-\alpha)\left[(1-\beta \gamma)-\beta^{2}(1-\gamma)\left(1-\Phi_{P}\right)\right]}{(1-\alpha)\left[(1-\beta \gamma)-\beta^{2}(1-\gamma)\left(1-\Phi_{P}\right)\right]+\Phi_{P} x_{P}(1-\beta \gamma)} .
\end{gathered}
$$

From the FOC $\left\{n_{2 t}\right\}$

$$
\begin{aligned}
& \left\{n_{2 t}\right\}:\left(1-x_{P}\right)\left(\frac{n_{P}}{1-n_{P}}\right)=\frac{(1-\alpha) \xi}{\Phi_{P}}+\beta \theta\left(\frac{1-\Phi_{P}}{\Phi_{P}}\right)+\beta^{2}(\gamma \theta-(1-\alpha) \xi(1-\gamma))\left(\frac{1}{1-\beta \gamma}\right)\left(\frac{1-\Phi_{P}}{\Phi_{P}}\right) \\
& \left(\frac{1-x_{P}}{x_{P}}\right)=\frac{(1-\alpha) \xi\left\{(1-\beta \gamma)-\beta^{2}(1-\gamma)\left(1-\Phi_{P}\right)\right\}+\beta \theta\left(1-\Phi_{P}\right)(1-\beta \gamma)+\beta^{2} \gamma \theta\left(1-\Phi_{P}\right)}{(1-\alpha)(1-\beta \gamma)-\beta^{2}(1-\alpha)(1-\gamma)\left(1-\Phi_{P}\right)}
\end{aligned}
$$

Hence,

$$
x_{P}=\frac{(1-\alpha)\left\{(1-\beta \gamma)-\beta^{2}(1-\gamma)\left(1-\Phi_{P}\right)\right\}}{(1+\xi)(1-\alpha)\left\{(1-\beta \gamma)-\beta^{2}(1-\gamma)\left(1-\Phi_{P}\right)\right\}+\beta \theta\left(1-\Phi_{P}\right)} .
$$

As long as $0<\left(1-\Phi_{P}\right)<1$ and $(1-\beta \gamma)-\beta^{2}(1-\gamma)>0$, we can easily show $0<\Phi_{P}$, $x_{P}, n_{P}<1$. Note,

$$
\begin{aligned}
(1-\beta \gamma)-\beta^{2}(1-\gamma) & =1-\beta \gamma-\beta^{2}+\beta^{2} \gamma \\
& =1-\beta^{2}-\beta \gamma(1-\beta) \\
& =(1-\beta)[1+\beta-\beta \gamma]
\end{aligned}
$$


which is clearly positive as long as $0<\gamma, \beta<1$, which is assumed. Now,

$$
\begin{aligned}
\left(1-\Phi_{P}\right) & =\frac{\alpha \beta(1-\beta \gamma)}{(1-\beta \gamma)\left[1-\beta^{2}(1-\gamma)(1-\mu)\right]-\beta^{3}(1-\gamma)[\gamma(1-\mu)-\alpha]} \\
& =\frac{\alpha \beta(1-\beta \gamma)}{(1-\beta \gamma)-\beta^{2}(1-\gamma)(1-\mu)+\alpha \beta^{3}(1-\gamma)}>0
\end{aligned}
$$

Since,

$$
\beta^{2}(1-\gamma)[(1-\mu)-\alpha \beta]<(1-\alpha \beta)(1-\beta \gamma)
$$

we get, $0<\Phi_{P}, x_{P}, n_{P}<1$.

\section{Growth rate at BGP}

$$
Y_{t}=\underline{A} \cdot\left(n_{2 t}^{1-\alpha}\right)^{\xi} K_{t}^{\alpha} n_{1 t}^{1-\alpha}
$$

At the balanced growth path (BGP),

$$
\begin{gathered}
g_{y_{P}}=g_{y_{P t+1}}=\frac{Y_{t+1}}{Y_{t}}=\frac{K_{t+1}^{\alpha}}{K_{t}^{\alpha}}=g_{k_{P t+1}}^{\alpha}=g_{k_{P}}^{\alpha}, \\
\text { and } g_{k_{P}}=\frac{K_{t+1}}{K_{t}}=\frac{I_{t} Z_{t}}{I_{t-1} Z_{t-1}}=g_{y_{P}} . g_{z_{P}} .
\end{gathered}
$$

Hence,

$$
g_{y_{P}}=g_{z_{P}}^{\frac{\alpha}{1-\alpha}}, g_{k_{P}}=g_{g_{P}}=g_{z_{P}}^{\frac{1}{1-\alpha}}
$$

Proposition (1)

$$
\begin{gathered}
\left.\widehat{g_{z_{P}}}=\widehat{\widehat{M_{P}}}\left\{(\tau)^{\mu}(1-\tau)^{1-\mu}\right\}^{(1-\gamma)}\right]^{\frac{1}{2-\gamma}}, \\
\frac{\partial \widehat{g_{z_{P}}}}{\partial \tau}=0, \\
\Rightarrow \mu(\tau)^{\mu-1}(1-\tau)^{1-\mu}-(1-\mu)(\tau)^{\mu}(1-\tau)^{-\mu}=0 \\
\Rightarrow \tau=\mu .
\end{gathered}
$$

\section{Appendix B: Agent's Version}

$$
\left\{K_{t+1}\right\}: \frac{-1}{Z_{t}}+\left(\frac{1}{1+r}\right) \frac{\alpha Y_{t+1}\left(1-\tau_{k}\right)}{K_{t+1}}=0 .
$$




$$
\begin{gathered}
\Rightarrow\left\{K_{t+1}\right\}: \frac{1}{Z_{t}}=\left(\frac{1}{1+r}\right) \frac{\alpha Y_{t+1}\left(1-\tau_{k}\right)}{K_{t+1}} \\
\left\{n_{1 t}\right\}: \frac{(1-\alpha) Y_{t}\left(1-\tau_{k}\right)}{n_{1 t}}-w_{t}\left(1-\tau_{k}\right)=0 \\
\Rightarrow\left\{n_{1 t}\right\}: w_{t}=\frac{(1-\alpha) Y_{t}}{n_{1 t}}
\end{gathered}
$$

Finally,

$$
\left\{n_{2 t}\right\}: w_{t}\left(1-\tau_{k}\right)=\left(\frac{\theta}{1+r}\right)\left(\frac{1}{n_{2 t}}\right) \sum_{j=0}^{\infty}\left(\frac{\gamma}{1+r}\right)^{j} I_{t+j+1} .
$$

\section{The Consumer's Problem}

$$
\begin{aligned}
\left\{c_{t}\right\} & : \frac{1}{c_{t}}=\lambda_{t}, \\
\left\{a_{t+1}\right\} & : \frac{\beta(1+r)}{c_{t+1}}=\frac{1}{c_{t}} \\
\left\{n_{1 t}\right\} & : \frac{w_{t}\left(1-\tau_{n}\right)}{c_{t}}=\frac{1}{1-n_{t}} \\
\left\{n_{2 t}\right\} & : \frac{w_{t}\left(1-\tau_{n}\right)}{c_{t}}=\frac{1}{1-n_{t}}
\end{aligned}
$$

From the firm's FOC $\left\{K_{t+1}\right\}$ :

$$
\left\{K_{t+1}\right\}: \frac{1}{Z_{t}}=\left(\frac{1}{1+r}\right) \frac{\alpha Y_{t+1}\left(1-\tau_{k}\right)}{K_{t+1}} .
$$

Substituting for $(1+r)$ from $\left\{a_{t+1}\right\}$

$$
\begin{aligned}
& \Rightarrow \frac{1}{Z_{t}}=\frac{\beta c_{t}}{c_{t+1}}\left[\frac{\alpha Y_{t+1}\left(1-\tau_{k}\right)}{K_{t+1}}\right] \\
& \Rightarrow\left\{K_{t+1}\right\}: \frac{1}{c_{t} Z_{t}}=\frac{\alpha \beta Y_{t+1}\left(1-\tau_{k}\right)}{c_{t+1} K_{t+1}}
\end{aligned}
$$

Similarly,

$$
\left\{n_{1 t}\right\}: \frac{1}{1-n_{t}}=\frac{(1-\alpha) Y_{t}\left(1-\tau_{n}\right)}{c_{t} n_{1 t}}
$$

and,

$$
\left\{n_{2 t}\right\}: \frac{1}{1-n_{t}}=\left(\frac{\beta \theta}{n_{2 t}}\right)\left(\frac{1-\tau_{n}}{1-\tau_{k}}\right) \sum_{j=0}^{\infty} \beta^{j} \gamma^{j} \frac{I_{t+j+1}}{c_{t+j+1}} .
$$


To summarize all FOCs,

$$
\begin{aligned}
\left\{K_{t+1}\right\} & : \frac{1}{c_{t} Z_{t}}=\frac{\alpha \beta Y_{t+1}\left(1-\tau_{k}\right)}{c_{t+1} K_{t+1}} \\
\left\{n_{1 t}\right\} & : \frac{1}{1-n_{t}}=\frac{(1-\alpha) Y_{t}\left(1-\tau_{n}\right)}{c_{t} n_{1 t}} \\
\left\{n_{2 t}\right\} & : \frac{1}{1-n_{t}}=\left(\frac{\beta \theta}{n_{2 t}}\right)\left(\frac{1-\tau_{n}}{1-\tau_{k}}\right) \sum_{j=0}^{\infty} \beta^{j} \gamma^{j} \frac{I_{t+j+1}}{c_{t+j+1}} .
\end{aligned}
$$

When

$$
\tau_{k}=\tau_{k}=\tau,
$$

we have

$$
\begin{aligned}
\left\{K_{t+1}\right\} & : \frac{1}{c_{t} Z_{t}}=\frac{\alpha \beta Y_{t+1}(1-\tau)}{c_{t+1} K_{t+1}} \\
\left\{n_{1 t}\right\} & : \frac{1}{1-n_{t}}=\frac{(1-\alpha) Y_{t}(1-\tau)}{n_{1 t}} \\
\left\{n_{2 t}\right\} & : \frac{1}{1-n_{t}}=\left(\frac{\beta \theta}{n_{2 t}}\right) \sum_{j=0}^{\infty} \beta^{j} \gamma^{j} \frac{I_{t+j+1}}{c_{t+j+1}} .
\end{aligned}
$$

\section{The Decision Rules}

We use the method of undetermined coefficients to obtain the decision rules

$$
\begin{aligned}
C_{t} & =\Phi_{C E} A Y_{t}, \\
I_{t} & =\left(1-\Phi_{C E}\right) A Y_{t} \\
n_{1 t} & =x_{C E} n_{C E} \\
n_{2 t} & =\left(1-x_{C E}\right) n_{C E} \\
n_{t} & =n_{C E},
\end{aligned}
$$

where,

$$
\begin{gathered}
\left\{Y_{t}-w_{t}\left(n_{1 t}+n_{2 t}\right)\right\}\left(1-\tau_{k}\right)+w_{t}\left(n_{1 t}+n_{2 t}\right)\left(1-\tau_{n}\right)=A Y_{t} . \\
\Rightarrow\left[\alpha\left(1-\tau_{k}\right)+(1-\alpha)\left(1-\tau_{n}\right)\right] Y_{t}+w_{t} n_{2 t}\left(\tau_{k}-\tau_{n}\right)=A Y_{t} \\
\Rightarrow\left[\alpha\left(1-\tau_{k}\right)+(1-\alpha)\left(1-\tau_{n}\right)\right] Y_{t}+\left\{\frac{\beta \theta A Y_{t}(1-\Phi)}{\left(1-\tau_{k}\right)(1-\beta \gamma)}\right\}\left(\tau_{k}-\tau_{n}\right)=A Y_{t}
\end{gathered}
$$




$$
\begin{gathered}
\Rightarrow \alpha\left(1-\tau_{k}\right)+(1-\alpha)\left(1-\tau_{n}\right)+\frac{\beta \theta A(1-\Phi)}{\left(1-\tau_{k}\right)(1-\beta \gamma)}\left(\tau_{k}-\tau_{n}\right)=A \\
\Rightarrow Y_{t}\left[\alpha\left(1-\tau_{k}\right)+(1-\alpha)\left(1-\tau_{n}\right)+\frac{\beta \theta A(1-\Phi)}{\left(1-\tau_{k}\right)(1-\beta \gamma)}\left(\tau_{k}-\tau_{n}\right)\right]=A Y_{t}, \\
\Rightarrow A=\left[\alpha\left(1-\tau_{k}\right)+(1-\alpha)\left(1-\tau_{n}\right)+\frac{\beta \theta(1-\Phi) A}{\left(1-\tau_{k}\right)(1-\beta \gamma)}\left(\tau_{k}-\tau_{n}\right)\right] .
\end{gathered}
$$

From the FOC of $\left\{K_{t+1}\right\}$

$$
\left\{K_{t+1}\right\}: \frac{1}{c_{t} Z_{t}}=\frac{\alpha \beta Y_{t+1}\left(1-\tau_{k}\right)}{c_{t+1} K_{t+1}}
$$

This implies,

$$
\begin{gathered}
\frac{1}{\Phi_{C E} A Y_{t} Z_{t}}=\frac{\alpha \beta Y_{t+1}\left(1-\tau_{k}\right)}{\Phi A Y_{t+1}\left(1-\Phi_{C E}\right) A Y_{t} Z_{t}} \\
\Rightarrow\left(1-\Phi_{C E}\right)=\frac{\alpha \beta\left(1-\tau_{k}\right)}{A} .
\end{gathered}
$$

Substituting for $\left(1-\Phi_{C E}\right) A$ from 53 into 52,

$$
\begin{aligned}
& \Rightarrow A=\left[\alpha\left(1-\tau_{k}\right)+(1-\alpha)\left(1-\tau_{n}\right)+\frac{\beta \theta\left(1-\Phi_{C E}\right) A}{\left(1-\tau_{k}\right)(1-\beta \gamma)}\left(\tau_{k}-\tau_{n}\right)\right] \\
& =\alpha\left(1-\tau_{k}\right)+(1-\alpha)\left(1-\tau_{n}\right)-\frac{\alpha \beta^{2} \theta\left(\tau_{n}-\tau_{k}\right)}{(1-\beta \gamma)} .
\end{aligned}
$$

When $\tau_{n}=\tau_{k}=\tau$

$$
\begin{aligned}
A & =[\alpha(1-\tau)+(1-\alpha)(1-\tau)] \\
& =(1-\tau) .
\end{aligned}
$$

From $\left\{n_{1 t}\right\}$ we get

$$
\begin{aligned}
\left\{n_{1 t}\right\} & : \frac{x_{C E} n_{C E}}{1-n_{C E}}=\frac{(1-\alpha) Y_{t}\left(1-\tau_{n}\right)}{\Phi_{C E} A Y_{t}} \\
\Rightarrow & \frac{x_{C E} n_{C E}}{1-n_{C E}}=\frac{(1-\alpha)\left(1-\tau_{n}\right)}{\Phi_{C E} A} \\
\Rightarrow & \frac{n_{C E}}{1-n_{C E}}=\frac{(1-\alpha)\left(1-\tau_{n}\right)}{x_{C E} \Phi_{C E} A} \\
\Rightarrow n_{C E} & =\frac{(1-\alpha)\left(1-\tau_{n}\right)}{(1-\alpha)\left(1-\tau_{n}\right)+x_{C E} \Phi_{C E} A} .
\end{aligned}
$$


From $\left\{n_{2 t}\right\}$

$$
\begin{aligned}
& \left\{n_{2 t}\right\}: \frac{(1-x) n_{C E}}{1-n_{C E}}=\frac{\beta \theta}{(1-\beta \gamma)}\left(\frac{1-\tau_{n}}{1-\tau_{k}}\right) \frac{\left(1-\Phi_{C E}\right)}{\Phi_{C E}} \\
\Rightarrow & \frac{(1-\alpha)\left(1-\tau_{n}\right)}{\Phi_{C E} A} \frac{\left(1-x_{C E}\right)}{x_{C E}}=\frac{\beta \theta}{(1-\beta \gamma)}\left(\frac{1-\tau_{n}}{1-\tau_{k}}\right) \frac{\left(1-\Phi_{C E}\right)}{\Phi_{C E}} \\
\Rightarrow & \frac{\left(1-x_{C E}\right)}{x_{C E}}=\frac{A \beta \theta\left(1-\Phi_{C E}\right)}{(1-\alpha)(1-\beta \gamma)\left(1-\tau_{k}\right)} . \\
\Rightarrow & x_{C E}=\frac{(1-\alpha)(1-\beta \gamma)\left(1-\tau_{k}\right)}{A \beta \theta\left(1-\Phi_{C E}\right)+(1-\alpha)\left(1-\tau_{k}\right)(1-\beta \gamma)} .
\end{aligned}
$$

Since,

$$
\begin{gathered}
A\left(1-\Phi_{C E}\right)=\alpha \beta\left(1-\tau_{k}\right), \\
\Rightarrow x_{C E}=\frac{(1-\alpha)(1-\beta \gamma)}{\alpha \beta^{2} \theta+(1-\alpha)(1-\beta \gamma)} .
\end{gathered}
$$

\section{Appendix C: Equal factor income taxes}

$$
\left(1-\Phi_{P}\right)=\frac{\alpha \beta(1-\beta \gamma)}{(1-\beta \gamma)-\beta^{2}(1-\gamma)(1-\mu)+\alpha \beta^{3}(1-\gamma)} .
$$

As $\mu$ increases, $(1-\mu)$ decreases, which implies $-(1-\mu)$ in the denominator increases and therefore $\left(1-\Phi_{P}\right)$ declines.

$$
\Rightarrow \frac{\partial \Phi_{P}}{\partial \mu}>0
$$

We will now look at $x_{P}$ :

$$
\begin{aligned}
\frac{1}{x_{P}} & =(1+\xi)+\frac{\beta \theta\left(1-\Phi_{P}\right)}{(1-\alpha)\left\{(1-\beta \gamma)-\beta^{2}(1-\gamma)\left(1-\Phi_{P}\right)\right\}} \\
& =(1+\xi)+\frac{\alpha \beta^{2} \theta}{(1-\alpha)\left\{(1-\beta \gamma)-\beta^{2}(1-\gamma)(1-\mu)\right\}} .
\end{aligned}
$$

As $\mu$ increases the term $\frac{\alpha \beta^{2} \theta}{(1-\alpha)\left\{(1-\beta \gamma)-\beta^{2}(1-\gamma)(1-\mu)\right\}}$ declines.

$$
\Rightarrow \frac{\partial x_{P}}{\partial \mu}>0 .
$$


We will now look at $n_{P}$ :

$$
\begin{aligned}
\frac{1}{n_{P}} & =1+\frac{x_{P} \Phi_{P}(1-\beta \gamma)}{(1-\alpha)\left\{(1-\beta \gamma)-\beta^{2}(1-\gamma)\left(1-\Phi_{P}\right)\right\}} \\
& =1+x_{P} \frac{\Phi_{P}(1-\beta \gamma)}{(1-\alpha)\left\{(1-\beta \gamma)-\beta^{2}(1-\gamma)\left(1-\Phi_{P}\right)\right\}} \\
& =1+\frac{x_{P}}{(1-\alpha)}\left[\frac{\Phi_{P}(1-\beta \gamma)}{\left\{(1-\beta \gamma)-\beta^{2}(1-\gamma)\left(1-\Phi_{P}\right)\right\}}\right] \\
& =1+\frac{x_{P}}{(1-\alpha)}\left[1-\frac{\alpha \beta\left((1-\beta \gamma)-\beta^{2}(1-\gamma)\right)}{(1-\beta \gamma)-\beta^{2}(1-\gamma)(1-\mu)}\right]
\end{aligned}
$$

We know that as $\mu$ increases, $\frac{x_{P}}{(1-\alpha)}$ increases because $\frac{\partial x_{P}}{\partial \mu}>0$. The term $\left[1-\frac{\alpha \beta\left((1-\beta \gamma)-\beta^{2}(1-\gamma)\right)}{(1-\beta \gamma)-\beta^{2}(1-\gamma)(1-\mu)}\right]$ also increases as $\mu$ increases. Hence

$$
\Rightarrow \frac{\partial n_{P}}{\partial \mu}<0
$$

In the competitive equilibrium under equal factor income taxes,

$$
\begin{aligned}
A & =1-\tau . \\
& \Rightarrow\left(1-\Phi_{C E}\right)=\alpha \beta \\
& \Rightarrow n_{C E}=\frac{(1-\alpha)}{(1-\alpha)+x_{C E} \Phi_{C E}} \\
& \Rightarrow x_{C E}=\frac{(1-\alpha)(1-\beta \gamma)}{\alpha \beta^{2} \theta+(1-\alpha)(1-\beta \gamma)} . \\
\Rightarrow \frac{g_{z_{P}}}{g_{z_{C E}}}= & \frac{\left(\left(1-x_{P}\right)^{\theta}\left(n_{P}\right)^{\theta}\left(1-\Phi_{P}\right)^{(1-\mu)(1-\gamma)}\right)^{\frac{1}{2-\gamma}}}{\left(\left(1-x_{C E}\right)^{\theta}\left(n_{C E}\right)^{\theta}\left(1-\Phi_{C E}\right)^{(1-\mu)(1-\gamma))^{\frac{1}{2-\gamma}}}\right.}
\end{aligned}
$$

$\Phi_{C E}$ is independent of $\mu$. However, since $0<\Phi_{C E}<1$,

$$
\Rightarrow \frac{\partial\left(1-\Phi_{C E}\right)^{(1-\mu)}}{\partial \mu}>0 .
$$

We know the term $\left(1-\Phi_{P}\right)$ is given by

$$
\left(1-\Phi_{P}\right)=\frac{\alpha \beta(1-\beta \gamma)}{(1-\beta \gamma)-\beta^{2}(1-\gamma)(1-\mu)+\alpha \beta^{3}(1-\gamma)}
$$

As $\gamma \rightarrow 1$,

$$
1-\Phi_{P} \rightarrow 1-\alpha \beta=1-\Phi_{C E}
$$


Similarly, as $\gamma \rightarrow 1$ and as $\xi \rightarrow 0$,

$$
\begin{aligned}
& x_{P} \rightarrow x_{C E} \\
& n_{P} \rightarrow n_{C E} . \\
& \Rightarrow g_{z_{C E}} \rightarrow g_{z_{P}} .
\end{aligned}
$$

\section{The no externalities case}

Suppose $\gamma=1$ and $\xi=0$. The FOC for the planner's version are then given by

$$
\begin{gathered}
\left\{C_{t}\right\}: \frac{1}{C_{t}}=\lambda_{t} \\
\left\{K_{t+1}\right\}: \frac{1}{C_{t} Z_{t}}=\frac{\alpha \beta Y_{t+1}(1-\tau)}{C_{t+1} K_{t+1}} \\
\left\{n_{1 t}\right\}: \frac{1}{1-n_{t}}=\frac{(1-\alpha) Y_{t}(1-\tau)}{C_{t} n_{1 t}} \\
\left\{n_{2 t}\right\}: \frac{1}{1-n_{t}}=\frac{\beta \theta}{n_{2 t}} \sum_{j=0}^{\infty} \beta^{j} \frac{I_{t+j+2}}{C_{t+j+2}} .
\end{gathered}
$$

The FOCs for the agents are summarized as follows,

$$
\begin{aligned}
\left\{K_{t+1}\right\} & : \frac{1}{c_{t} Z_{t}}=\frac{\alpha \beta Y_{t+1}\left(1-\tau_{k}\right)}{c_{t+1} K_{t+1}} \\
\left\{n_{1 t}\right\} & : \frac{1}{1-n_{t}}=\frac{(1-\alpha) Y_{t}\left(1-\tau_{n}\right)}{c_{t} n_{1 t}} \\
\left\{n_{2 t}\right\} & : \frac{1}{1-n_{t}}=\left(\frac{\beta \theta}{n_{2 t}}\right)\left(\frac{1-\tau_{n}}{1-\tau_{k}}\right) \sum_{j=0}^{\infty} \beta^{j} \frac{I_{t+j+1}}{c_{t+j+1}} .
\end{aligned}
$$

The FOCs coincide when

$$
\tau_{n}=\tau_{k}=\tau .
$$

This implies, the optimal solutions always coincide for the planner and for the agent under 
equal factor income taxes. For the planner, under no externalities,

$$
\begin{aligned}
\left(1-\Phi_{P}\right) & =\alpha \beta \\
\Phi_{P} & =1-\alpha \beta \\
n_{P} & =\frac{(1-\alpha)}{(1-\alpha)+\Phi_{P} x_{P}} \\
x_{P} & =\frac{(1-\alpha)(1-\beta)}{(1-\alpha)(1-\beta)+\alpha \beta^{2} \theta} .
\end{aligned}
$$

Similarly,for the agents,

$$
\begin{aligned}
A & =\alpha\left(1-\tau_{k}\right)+(1-\alpha)\left(1-\tau_{n}\right)-\frac{\alpha \beta^{2} \theta\left(\tau_{n}-\tau_{k}\right)}{(1-\beta)} \\
\left(1-\Phi_{C E}\right) & =\frac{\alpha \beta\left(1-\tau_{k}\right)}{A} \\
\Phi_{C E} & =1-\frac{\alpha \beta\left(1-\tau_{k}\right)}{A} \\
n_{C E} & =\frac{(1-\alpha)\left(1-\tau_{n}\right)}{(1-\alpha)\left(1-\tau_{n}\right)+x_{C E} \Phi_{C E} A} \\
x_{C E} & =\frac{(1-\alpha)(1-\beta)}{\alpha \beta^{2} \theta+(1-\alpha)(1-\beta)} .
\end{aligned}
$$

Only equal factor income taxes under the no externality case, yields the planner's growth rate, except under a very restrictive parametric restriction,

$$
\left(\frac{1-\beta}{\beta}\right)^{2}=\theta .
$$

Under this equal factor income taxes are one among infinitely many factor income tax combinations that decentralize the planner's growth rate. We can show this as follows.

For growth equalization, we need

$$
n_{C E}=\frac{(1-\alpha)\left(1-\tau_{n}\right)}{(1-\alpha)\left(1-\tau_{n}\right)+x_{C E} \Phi_{C E} A}=n_{P}
$$




$$
\begin{aligned}
& \Rightarrow \frac{x_{C E} \Phi_{C E} A}{\left(1-\tau_{n}\right)}=\Phi_{P} x_{P} \\
& \Rightarrow \frac{\Phi_{C E} A}{\left(1-\tau_{n}\right)}=\Phi_{P} \\
& \Rightarrow \frac{A-\alpha \beta\left(1-\tau_{k}\right)}{\left(1-\tau_{n}\right)}=1-\alpha \beta \\
& \Rightarrow A-\alpha \beta\left(1-\tau_{k}\right)=(1-\alpha \beta)\left(1-\tau_{n}\right) \\
& \Rightarrow \alpha\left(1-\tau_{k}\right)+(1-\alpha)\left(1-\tau_{n}\right)-\frac{\alpha \beta^{2} \theta\left(\tau_{n}-\tau_{k}\right)}{(1-\beta)}-\alpha \beta\left(1-\tau_{k}\right)=(1-\alpha \beta)\left(1-\tau_{n}\right) .
\end{aligned}
$$

Hence,

$$
(\alpha-\alpha \beta)\left(1-\tau_{k}\right)-(\alpha-\alpha \beta)\left(1-\tau_{n}\right)=\frac{\alpha \beta^{2} \theta\left(\tau_{n}-\tau_{k}\right)}{(1-\beta)}
$$

which implies

$$
(1-\beta)\left(\tau_{n}-\tau_{k}\right)=\frac{\beta^{2} \theta\left(\tau_{n}-\tau_{k}\right)}{(1-\beta)} .
$$

Clearly, as long as $\frac{(1-\beta)}{\beta} \neq \sqrt{\theta}, \tau_{n}=\tau_{k}$ always decentralizes planner's growth rates. When $\frac{(1-\beta)}{\beta}=\sqrt{\theta}$, any factor income tax combination decentralizes planner's growth rate. As noted in the text, for $\theta=0.2$, (or $\theta=0.5$, as we have used in our numerical exercise) as in Huffman, the value of $\beta=0.69098$ is very small and is not consistent with the literature. (When or $\theta=0.5, \beta=0.58579$ which is even smaller. ). We therefore rule out the possibility of equality.

\section{Appendix D: Agent's Welfare}

We know

$$
\begin{gathered}
C_{t}=\Phi_{C E} Y_{t} A\left(\tau_{k}, \tau_{n}\right) \\
\Rightarrow \frac{C_{t}}{C_{t-1}}=\frac{Y_{t}}{Y_{t}}=g_{y} \\
\Rightarrow g_{c, C E}=g_{y, C E} .
\end{gathered}
$$


Since $g_{c}$ is a constant, $C_{t}=C_{0} g_{c}^{t}$. On the BGP, the supply of labor is the same across time. We denote welfare by $\Lambda$, where,

$$
\begin{gathered}
\Lambda=\sum_{j=0}^{\infty} \beta^{t}\left[\log C_{t}+\log \left(1-n_{C E}\right)\right] \\
\Lambda=\sum_{j=0}^{\infty} \beta^{t} \log C_{t}+\frac{\log \left(1-n_{C E}\right)}{1-\beta} \\
\Rightarrow \Lambda=\log C_{o}+\beta \log C_{1}+\beta^{2} \log C_{2}+\beta^{3} \log C_{3}+\beta^{4} \log C_{4}+\ldots \ldots . .+\frac{\log \left(1-n_{C E}\right)}{1-\beta} \\
\Rightarrow \Lambda=\frac{\log C_{o}}{1-\beta}+\frac{\beta^{2}}{1-\beta} \log g_{c, C E}+\frac{\log \left(1-n_{C E}\right)}{1-\beta} \\
\Rightarrow \Lambda=\frac{\log \left[\Phi_{C E} Y_{t} A\left(\tau_{k}, \tau_{n}\right)\right]}{1-\beta}+\frac{\beta^{2} \alpha}{(1-\beta)(1-\alpha)} \log g_{c, C E}+\frac{\log \left(1-n_{C E}\right)}{1-\beta} \\
\Rightarrow \Lambda=\frac{\log \left[\Phi_{C E}\right]}{1-\beta}+\frac{\log \left[Y_{0}\right]}{1-\beta}+\frac{\log \left[A\left(\tau_{k}, \tau_{n}\right)\right]}{1-\beta}+\frac{\beta^{2} \alpha}{(1-\beta)(1-\alpha)} \log g_{c, C E}+\frac{\log \left(1-n_{C E}\right)}{1-\beta} .
\end{gathered}
$$




\section{Figures}

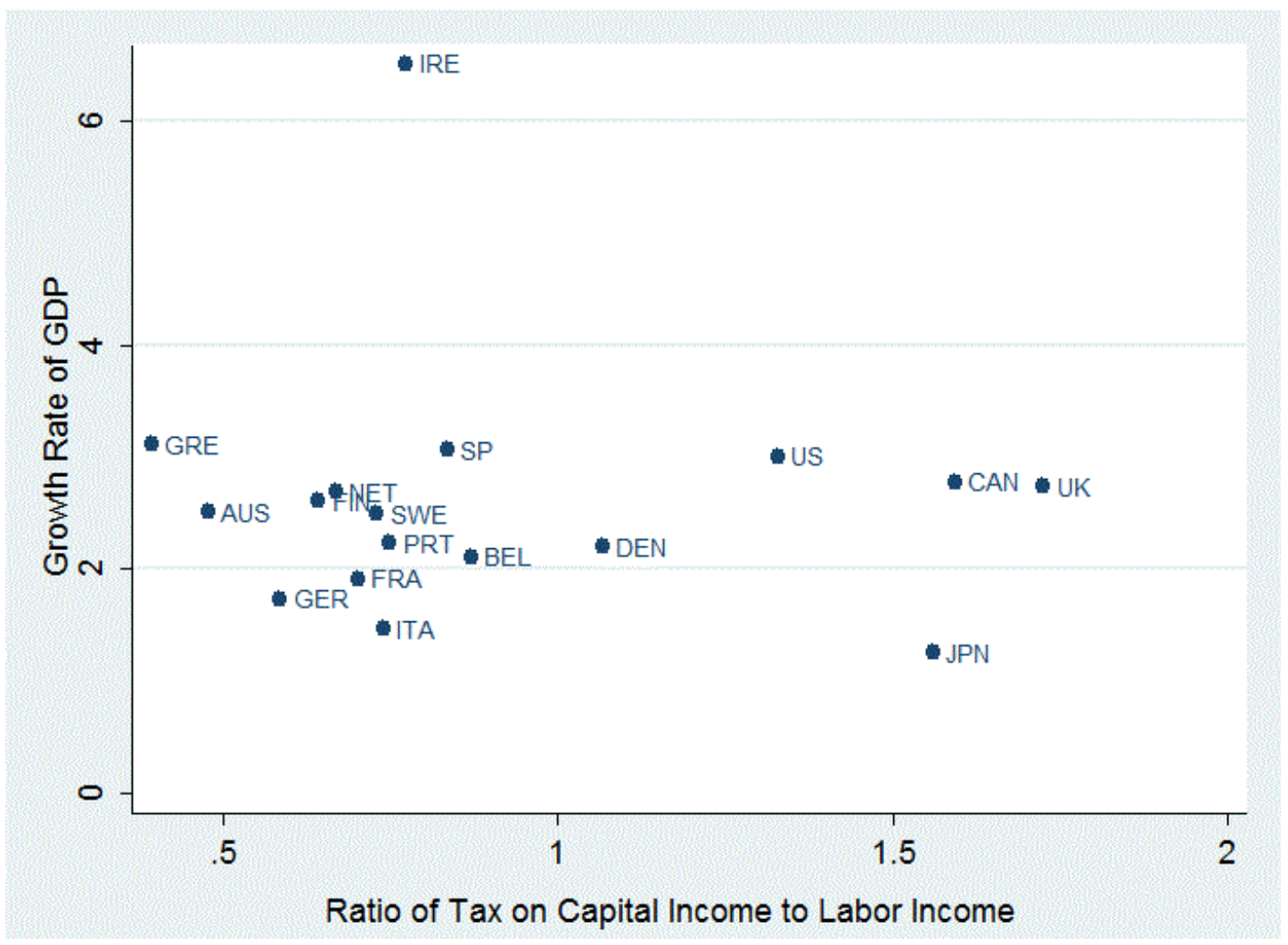

Figure 1: Average growth rates for select OECD economies versus the ratio of tax on capital income to tax on labor income 


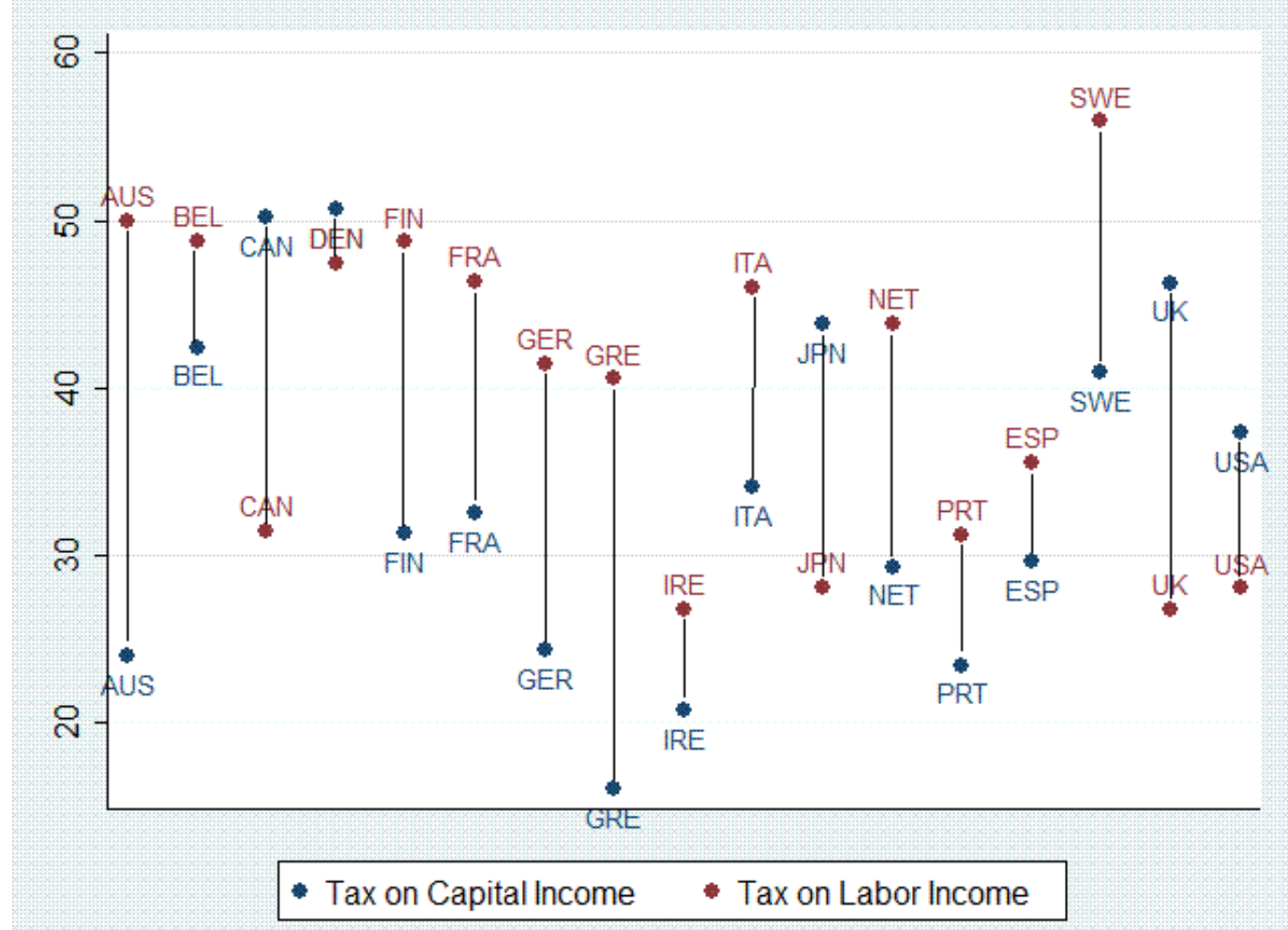

Figure 2: Average factor income tax rates for select OECD economies 

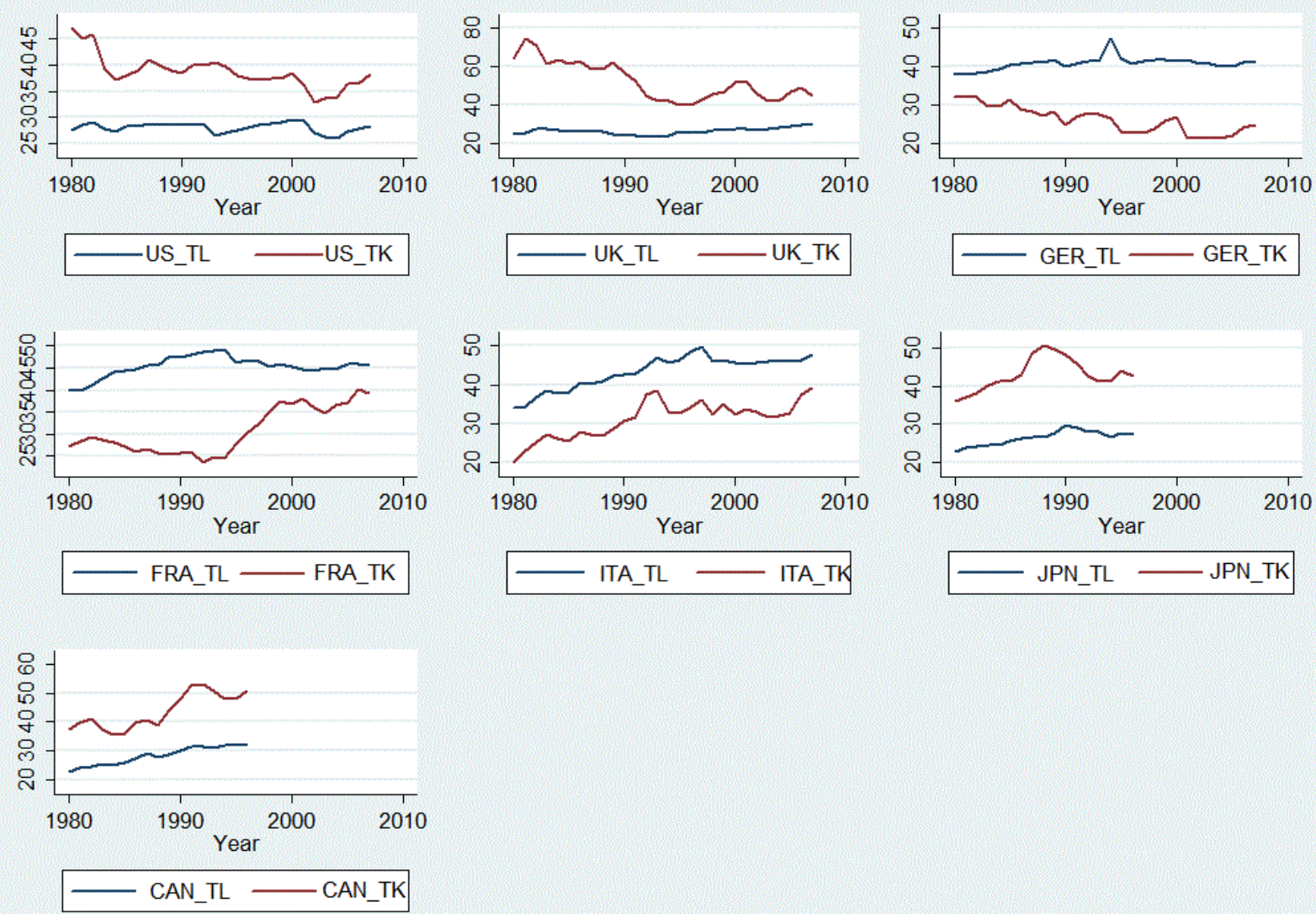

Figure 3: Time trend of factor income taxes for G7 economies 


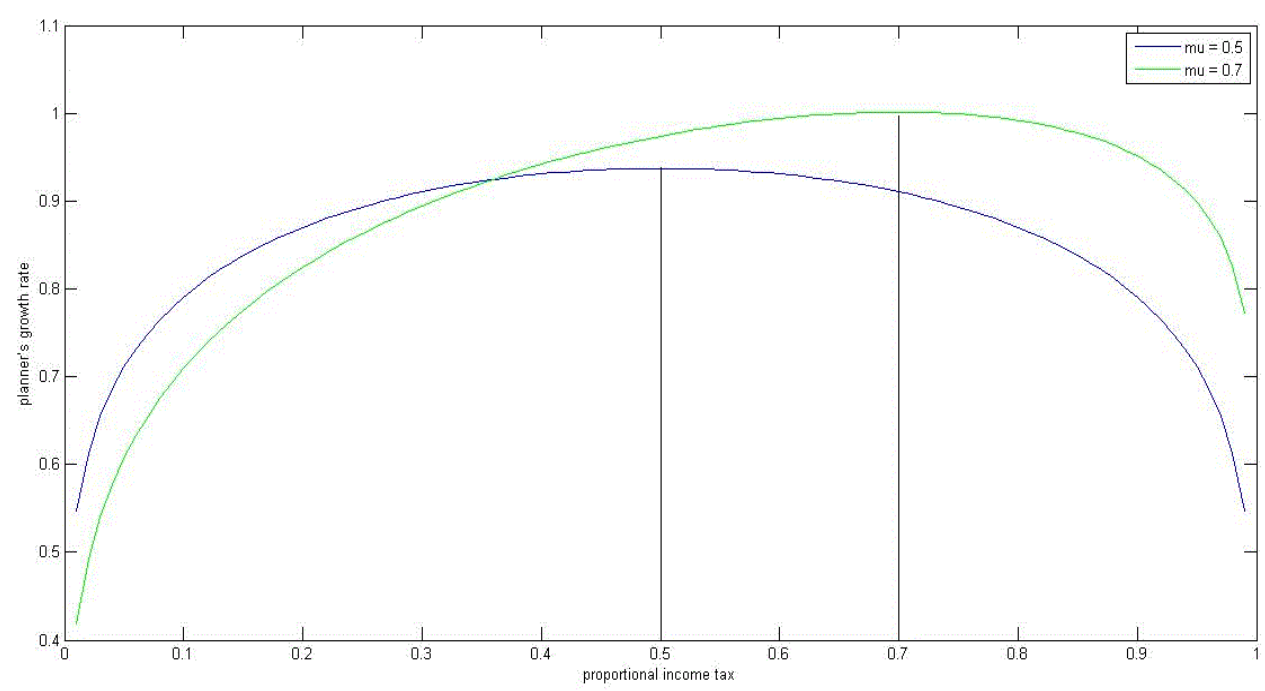

Figure 4: Comparative statics - planner's growth rate
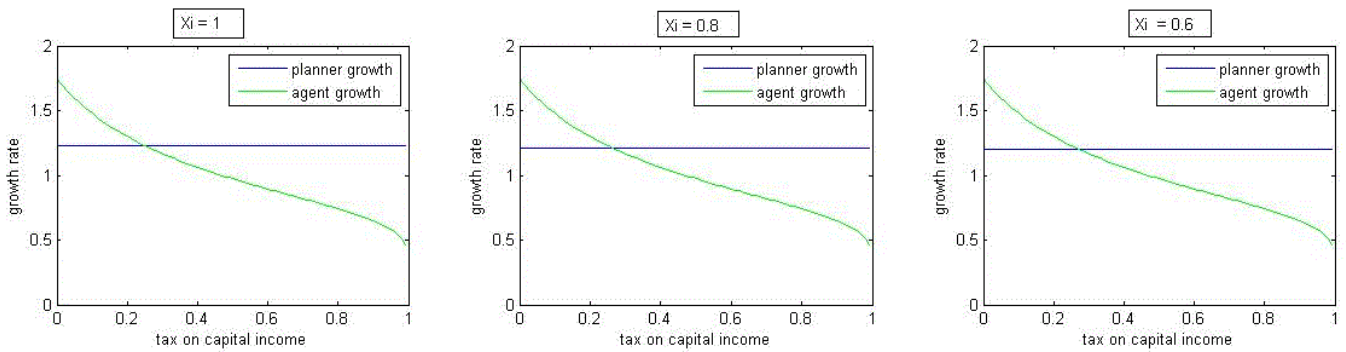

$\mathrm{Xi}=0.4$
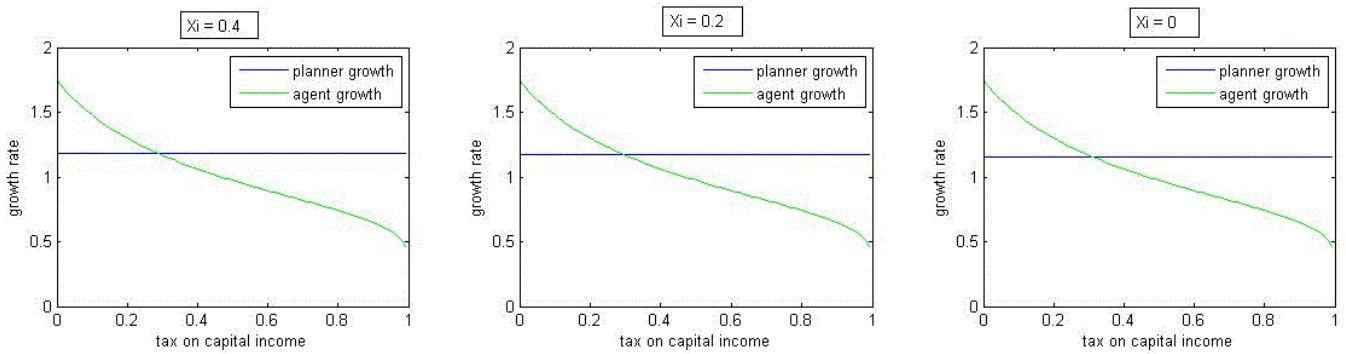

Figure 5: $\gamma=0.8, \mu=0.2, \theta=0.5$ 

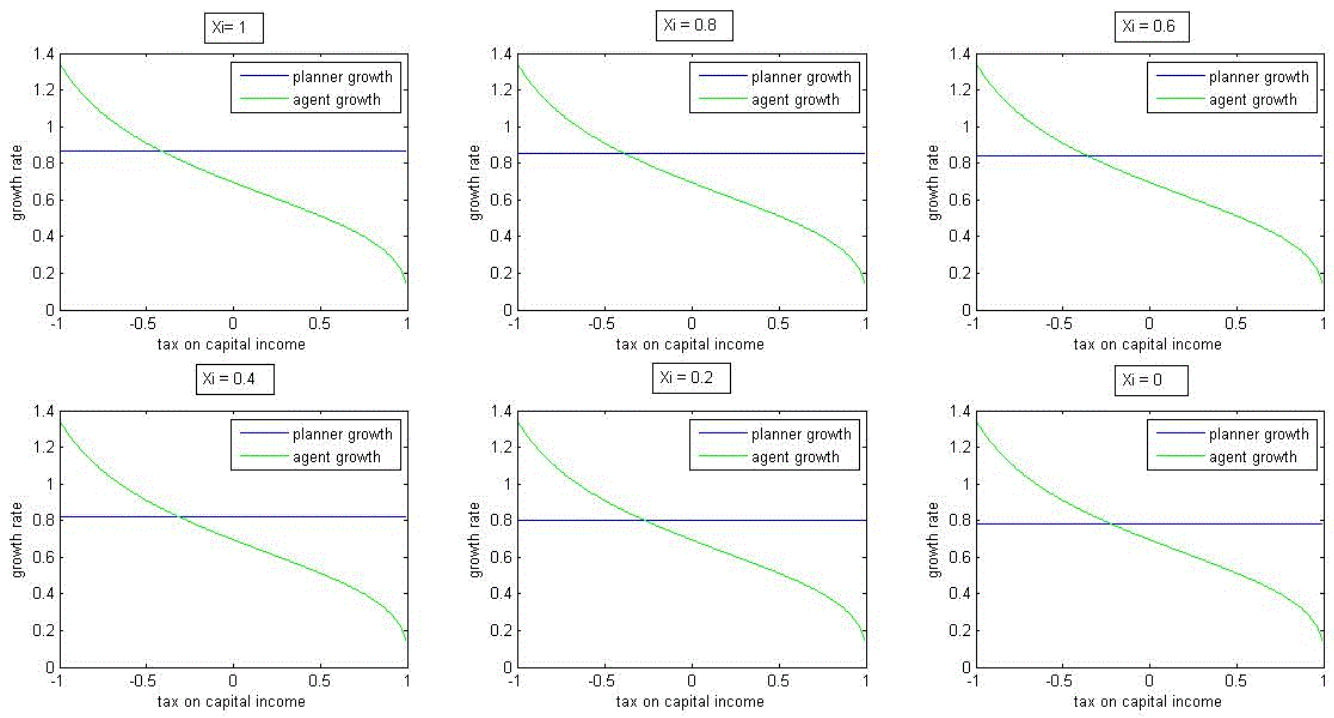

Figure 6: $\gamma=0.4, \mu=0.2, \theta=0.5$
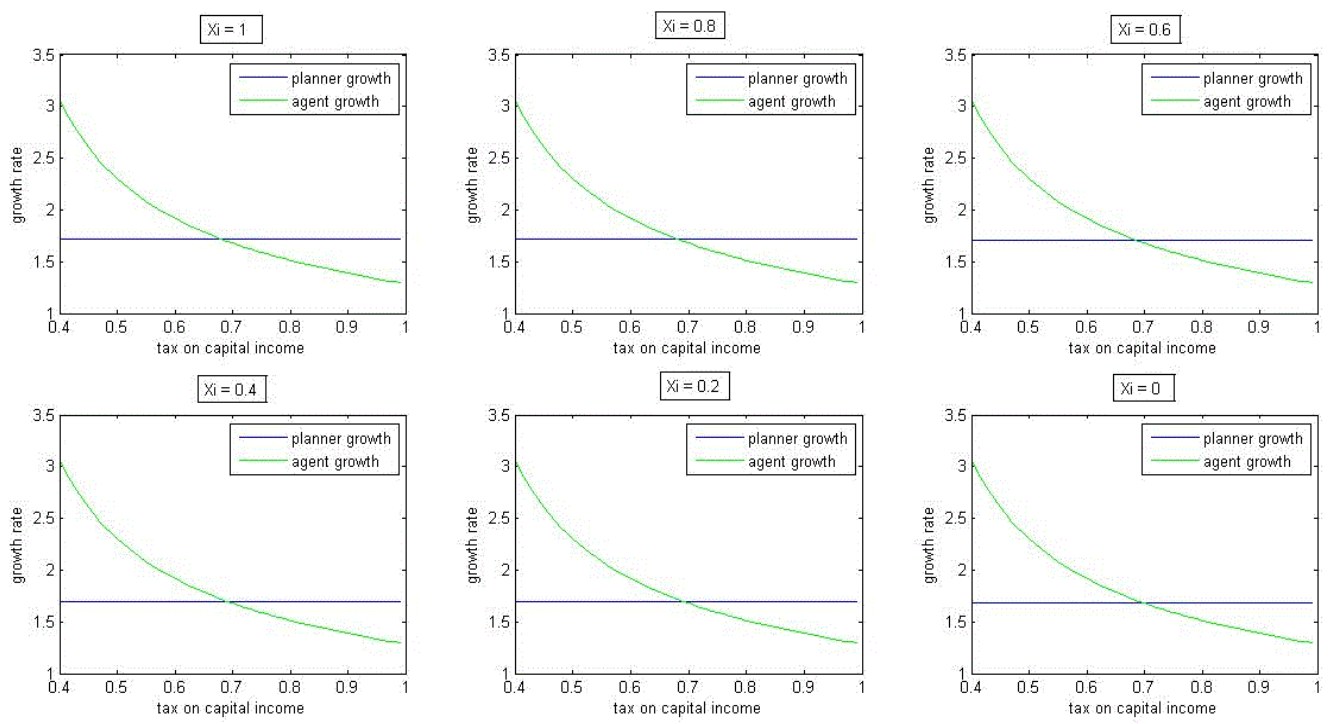

Figure 7: $\gamma=1, \theta=0.5$ 

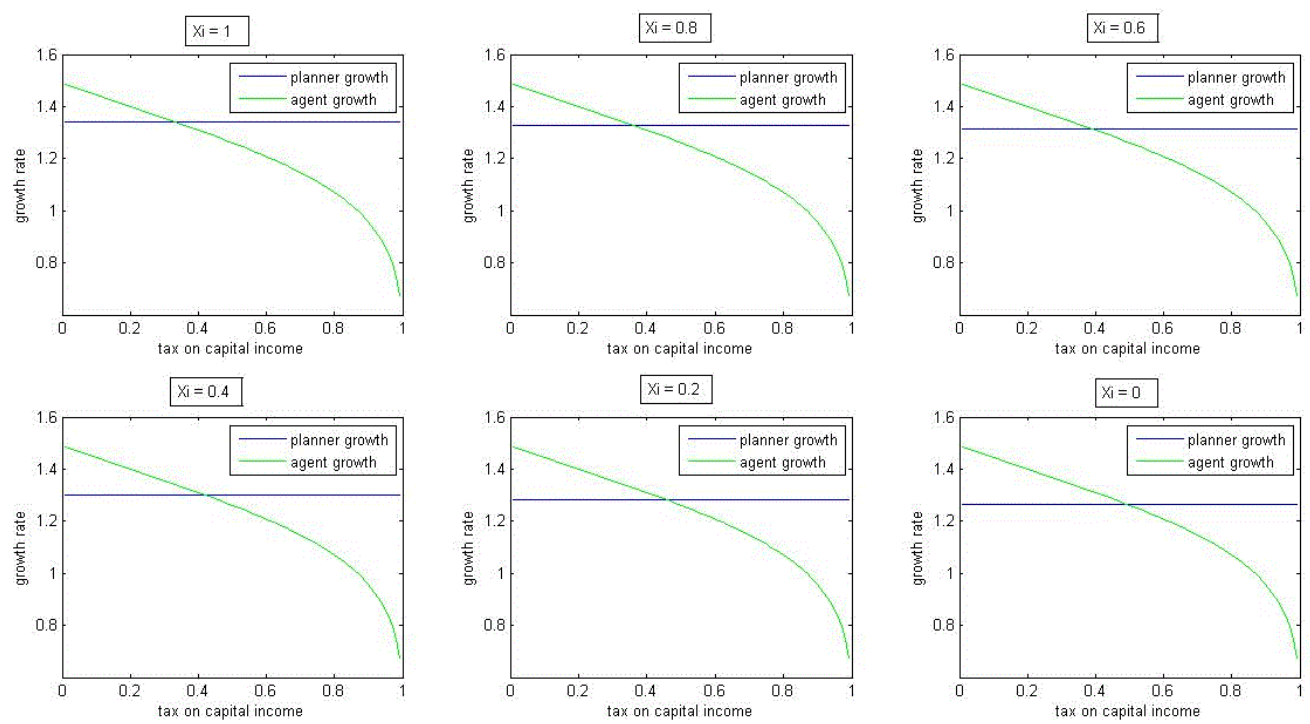

Figure 8: $\alpha=0.7, \gamma=0.4, \mu=0.6, \theta=0.5$

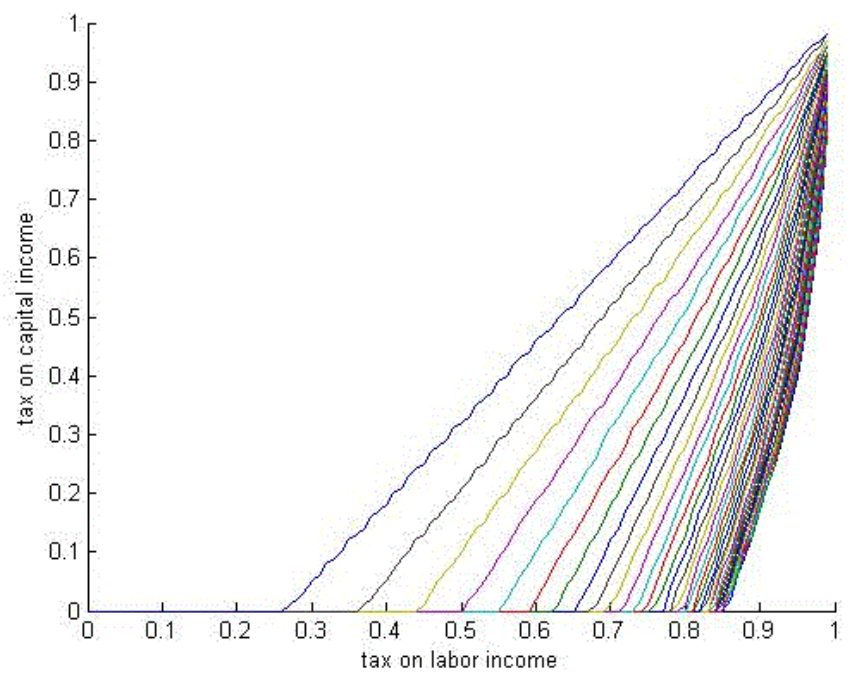

Figure 9: Growth restoring factor income taxes: $\xi=1$ 


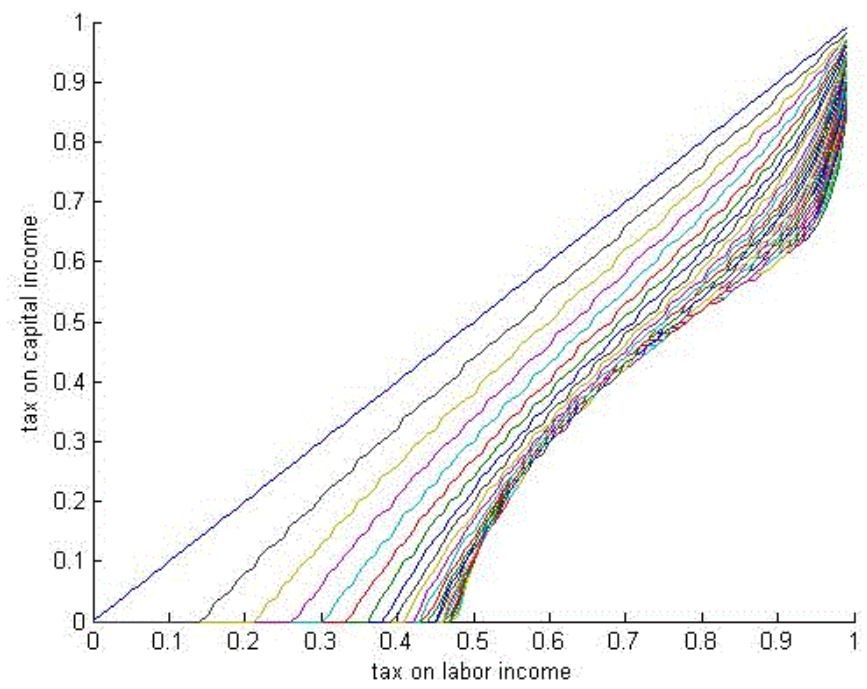

Figure 10: Growth restoring factor income taxes: $\xi=0$

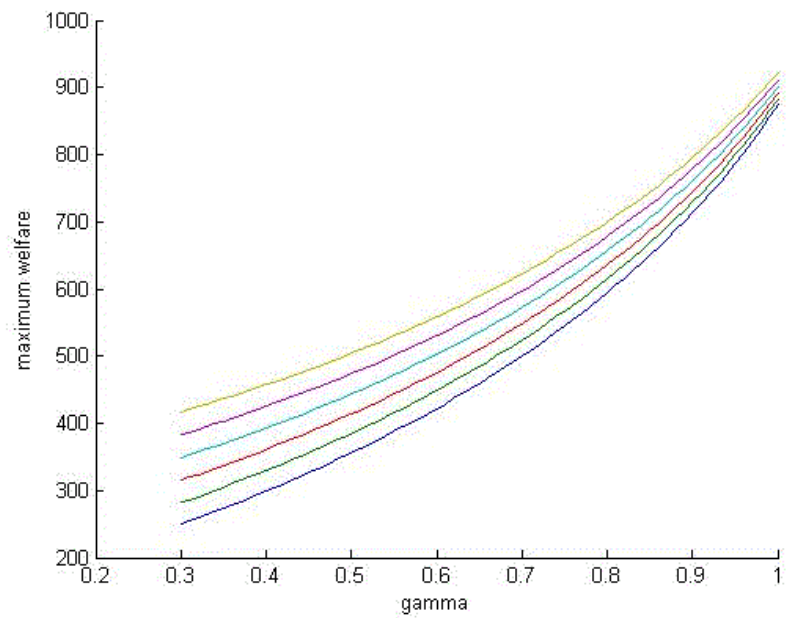

Figure 11: Maximum welfare for changing values of $\gamma$ 


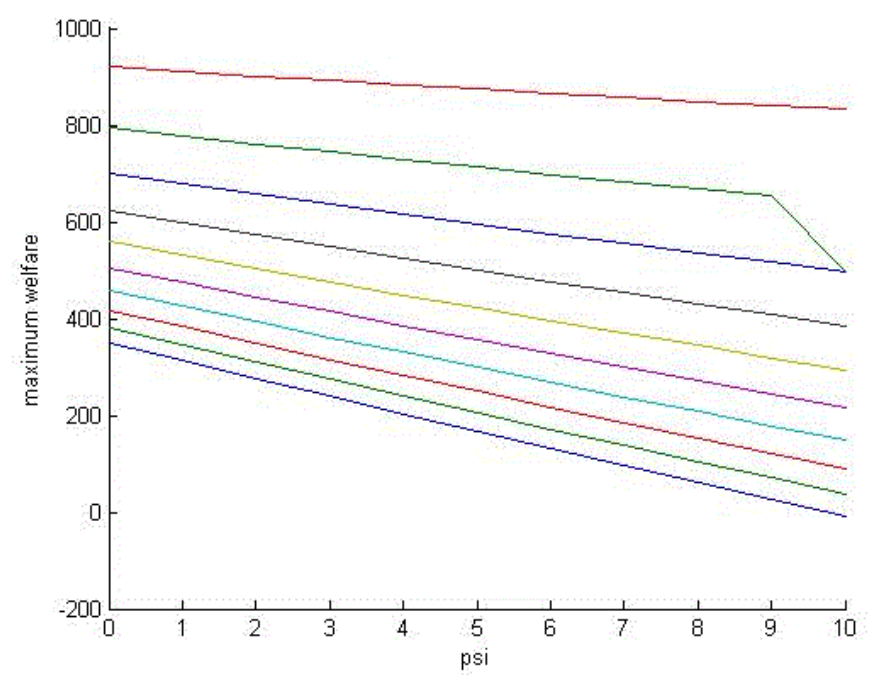

Figure 12: Maximum welfare for changing values of $\xi$
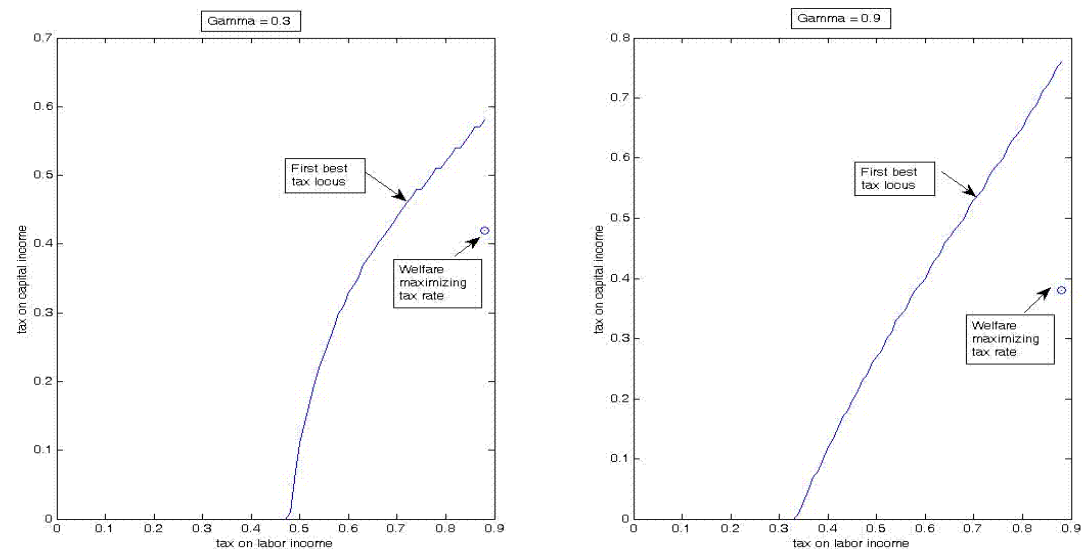

Figure 13: Growth versus welfare: $\xi=0$ 

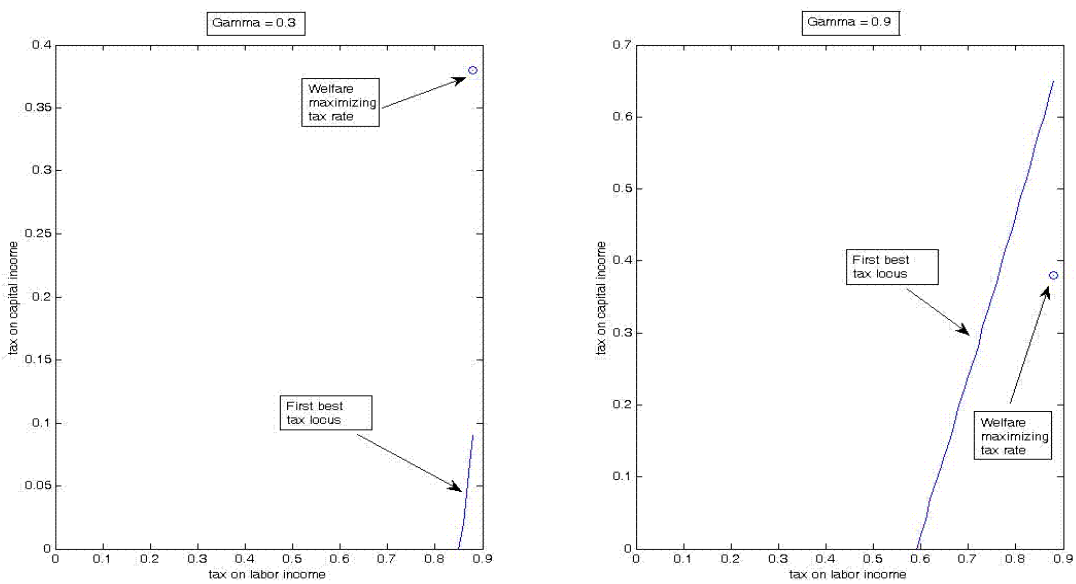

Figure 14: Growth versus welfare: $\xi=1$ 